\title{
Curcumin and Ethanol Effects in Trembler-J Schwann Cell Cul-
} ture

\author{
Lucia Vázquez Alberdi 1,*, Gonzalo Rosso 2,3, Lucia Velóz ${ }^{4}$, Carlos Romeo 5, Joaquina Farias ${ }^{6}$, María Vittoria Di \\ Tomaso ${ }^{7}$, Miguel Calero ${ }^{8}$ and Alejandra Kun ${ }^{1,9, *}$
}

1 Laboratorio de Biología Celular del Sistema Nervioso Periférico, Departamento de Proteínas y Ácidos Nucleicos, Instituto de Investigaciones Biológicas Clemente Estable, 11600 Montevideo, Uruguay; lvazquez@iibce.edu.uy (L.V.A.)

2 Max-Planck-Institute for the Science of Light \& Max-Planck-Zentrum für Physik und Medizin, 91058 Erlangen, Germany; gonzalo.rosso@mpl.mpg.de (G.R.)

3 Institute of Physiology II, University of Münster, 48149 Münster, Germany

4 Sección Biología Celular, Facultad de Ciencias, Universidad de la República, 11400 Montevideo, Uruguay; lveloz@fcien.edu.uy (L.V.)

5 Departamento de Proteínas y Ácidos Nucleicos, Instituto de Investigaciones Biológicas Clemente Estable, 11600 Montevideo, Uruguay; carlosj.romeo@gmail.com (C.R.)

6 Espacio de Biología Vegetal del Noreste, Centro Universitario de Tacuarembó, CENUR Noreste, Universidad de la República, 45000 Tacuarembó, Uruguay; joaquina.farias@cut.edu.uy (J.F.)

7 Departamento de Genética, Instituto de Investigaciones Biológicas Clemente Estable, 11600, Montevideo, Uruguay; marvi@iibce.edu.uy (M.V.D.T.)

8 Unidad de Encefalopatías Espongiformes, UFIEC, CIBERNED, CIEN Foundation, Queen Sofia Foundation Alzheimer Center, Instituto de Salud Carlos III, 28031 Madrid, Spain; mcalero@isciii.es (M.C.)

9 Sección Bioquímica, Facultad de Ciencias, Universidad de la República, 11400 Montevideo, Uruguay

* Correspondence: lvazquez@iibce.edu.uy (L.V.A.) akun@fcien.edu.uy (A.K.); Tel.: +598-2487-1616; Fax: +5982487-5461

\begin{abstract}
Charcot-Marie-Tooth (CMT) syndrome is the most common progressive human motor and sensory peripheral neuropathy. CMT type $1 \mathrm{E}$ is a demyelinating neuropathy affecting Schwann cells due to pmp22 mutations, modelized by Trembler-J mice. Curcumin, a natural polyphenol compound obtained from turmeric (Curcuma longa), exhibits dose- and time-varying antitumor, antioxidant and neuroprotective properties, however, the neurotherapeutic actions of curcumin still remain elusive. Here, we propose curcumin as a possible natural treatment capable of enhancing cellular detoxification mechanisms, resulting in an improvement of the neurodegenerative Trembler-J phenotype. Using a refined method for obtaining enriched Schwann cell cultures, we evaluated the neurotherapeutic action of low dose curcumin treatment on the PMP22 expression, and on the chaperones (HSF1 and Hsp27) and autophagy/mTOR (HDAC6 and ribosomes) pathways in Trembler-J and wild-type genotypes. In wild-type Schwann cells, the action of cur-cumin resulted in strong stimulation of the chaperone and macroautophagy pathway, whereas the modulation of ribophagy showed a mild effect. However, despite the promising neuroprotective effects for the treatment of neurological diseases, we report (demonstrate?) that the action of curcumin in Trembler-J Schwann cells could be impaired due to the irreversible impact of ethanol used as a common curcumin vehicle necessary for administration. These results contribute to expand our still limited understanding of PMP22 biology in neurobiology, and expose the intrinsic lability of the neurodegenerative Trembler-J genotype. Furthermore, they unravel interesting physiological mechanisms of cellular resilience relevant for to the pharmacological treatment of the neurodegenerative Tremble J phenotype with curcumin and ethanol. We conclude that the analysis of the effects of the vehicle itself is an essential and in-escapable step to comprehensibly assess the own effects and full potential of curcumin treatment for therapeutic purposes.
\end{abstract}

Keywords: CMT1E; Trembler-J; curcumin; Hsps; autophagy; mTOR

\section{Introduction}


The group of human hereditary peripheral neuropathies, known as Charcot-MarieTooth (CMT) disease, has a prevalence of 1/2500 [1]. Within the CMTs, demyelinating neuropathies (CMT1) have mutations that alter the structural integrity of myelin [2]. Up to $5 \%$ of all CMT1s integrate the group of CMT1E, myelinopathies caused by different point mutations in the pmp22 gene, which encodes for the compact myelin protein PMP22 [3].

The Trembler J (TrJ/+) mouse is an animal model of CMT1E [4-7], carrying the same spontaneous mutation in pmp22 as that found in a human family [8]. Under normal conditions, only $20 \%$ of PMP22 is inserted into the membrane, with chaperone assistance, at the cost of high energy expenditure (by the synthesis of unused PMP22 and for the maintenance of the proteasome machinery in charge of eliminating the protein surplus) $[9,10]$. In disease, the percentage of myelin that is inserted is even lower, so it is common to find intracellular PMP22 aggregates in Schwann cells (SCs) of TrJ/+ mice [11], interfering with the regular protein transport. Thus, the peripheral nerve fibers from the neurodegenerative phenotype in TrJ/+ show altered autophagic-lysosomal pathways, PMP22 cytoplasmic aggregation, increased ribosome and translational activity [6,12-16].

One of the mechanisms underlying cellular stress situations is the response by Heat Shock Proteins (Hsps) [17-21]. HSF1, the main regulator of the Hsps, is activated by mTOR under stress [19,22] and its inhibition prevents autophagosome formation [23]. Hsp27, recognized for its dual role in normal situations and tumor processes [24-27], has also been pointed out as a possible target of action for neurodegenerative diseases [28]. In stressful situations, such as the accumulation of intracellular proteins, Hsp27 activates and modulates AKT action, mTOR main activator [29-31]. It has also been reported that Hsp70, another member of the Hsps family, assists in the processing of PMP22 aggregates in TrJ/+ through Golgi apparatus and their release into Rab7-positive vesicles to the lysosome [32]. It has been observed, both in vivo and in vitro, that there is co-localization of Hsps with PMP22 aggregates [6,32]. Also, beneficial effects of autophagy, promoted by chaperones, preventing the accumulation of misfolded PMP22 have been reported in $\mathrm{TrJ} /+$ [33]. Also, in CMT2, deacetylase HDAC6 has been signaled as a potential therapeutic target for amelioration of the neurodegenerative phenotype, reversing motor and sensory deficits induced by Hsp27 activation [34].

A possible cellular and molecular perspective on the therapeutics of these until now incurable hereditary conditions may focus on cellular drainage or detoxification promoted on the autophagic-lysosomal and UPS-chaperone pathways, together with inhibition or reduction of the mTOR pathway. Furthermore, decreased energy availability is a common key player for the modulation of these pathways. For this reason, caloric restriction (CR) at the neuromotor level has been proposed as a valid therapeutic approach for the alleviation of neurodegenerative conditions (including peripheral neuropathies) [35-38]. Our group demonstrated that dietary CR activates canonical autophagic pathways by decreasing the levels of aggregated PMP22 and increasing ribophagy in TrJ/+ and in wild-type $(+/+)$ nerves (manuscript in preparation).

$\mathrm{CR}$ can be emulated, under certain conditions, by effector molecules of the aforementioned pathways [39-43]. Among them, curcumin, a polyphenol extracted from Curcuma longa (Linnaeus, Species Plantarum 1:2. 1753), has shown promising results [44,45]. This compound is used as an antitumor, anti-inflammatory, antioxidant, among other beneficial effects. This wide spectrum of curcumin applications depends mainly on the dosage used and the time of application of the treatments. For example, at high concentrations, which in culture range from $25 \mu \mathrm{M}$ to $160 \mu \mathrm{M}$, curcumin is used as a potent anti-tumoral $[46,47]$. At low concentrations, it decreases reactive oxygen species (ROS) (in myoblast cell cultures $4 \mu \mathrm{M}$ curcumin and SC from 0.001 to $1 \mu \mathrm{M}$ curcumin) [48,49], and promotes autophagy by inhibiting acetyltransferases (GBM2 glioma cell line, $10 \mu \mathrm{M}$ curcumin) [44,50] and cell regeneration (primary myoblast culture, $1 \mu \mathrm{M}$ curcumin) [51,52]. Interestingly, in $\operatorname{TrJ}$ mice, there is evidence that curcumin treatment can improve the neurodegenerative phenotype [53]. On the other hand, CR activates the autophagy process, prevents the formation, and promotes the elimination of PMP22 aggregates in cultured SCs [54]. 
However, little is known about the effect of curcumin and ethanol used as curcumin vehicle in the modulation of PMP22 aggregates, and whether this effect could activate effector molecules in SCs ameliorating the neurodegenerative condition of TrJ mice.

In the present work, we set up a new method to obtain enriched cultures in $+/+$ and $\mathrm{TrJ} /+\mathrm{SC}$ s to comprehensibly investigate the effects of curcumin and ethanol. After isolation, we studied the effects of low doses of curcumin on proliferating SCs by evaluating the expression of PMP22 and the modulation of proteins involved in autophagy/mTOR (HDAC6, ribosomes) and the heat shock response (HSF1 and Hsp27). The main results obtained allowed us to visualize specific responses associated with the wild-type genotype, which were different from those observed in the neurodegenerative genotype. The effect of alcohol as a vehicle for solubilization of curcumin in the culture medium was especially scrutinized and the possible significance of its impact is discussed, contrasting them with literature data.

\section{Materials and Methods}

\subsection{Animals}

C57BL wild-type (+/+) and Trembler-J (TrJ/+) mice were obtained from the B6.D2Pmp22 ${ }^{\mathrm{Tr}-\mathrm{J}} / \mathrm{J}$ reservoir (JAX stock \#002504, Jackson Laboratories). The colony was maintained and replicated at the Laboratory of Animal Experimentation of the Clemente Estable Biological Research Institute (IIBCE, MEC). The animal experimentation protocol was approved by the CEUA - IIBCE ethics committee (protocol No.: 002a/10/2020). Mice were housed in a controlled environment (12 h light/dark cycle) and a mean temperature of 21 $\pm 3^{\circ} \mathrm{C}$ with free access to food and water. Mice were weaned at 21 days of age. For this work, 3-month-old male mice $(+/+, \mathrm{n}=3$; $\operatorname{Tr} \mathrm{J} /+, \mathrm{n}=3)$ were used.

\subsection{Primary culture enriched in SCS}

Sciatic nerve fibers were dissected as previously described [14]. Briefly, after the cervical dislocation, the mouse was placed in the ventral decubitus position and sprayed with $70 \%$ ethanol (EtOH). Both sciatic nerves were dissected using surgical scissors. The nerves were then immersed in Dulbecco's Modified Eagle's Medium (Cat\#: DMEM-HSPTA, Capricorn, Ebsdorfergrund, Germany) supplemented with 10\% Bovine Serum (FBS, Cat\#: 26140079, Gibco ${ }^{\mathrm{TM}}$, Massachusetts, USA); $5 \mu \mathrm{g} / \mathrm{ml}$-penicillin $/ 5 \mu \mathrm{g} / \mathrm{ml}$-streptomycin $/ 10$ $\mu \mathrm{g} / \mathrm{ml}$-neomycin (PSN 1X, Cat\#: 15640055, Gibco ${ }^{\text {TM }}$, Massachusetts, USA) and 2 mM GlutaMAX ${ }^{\mathrm{TM}}$ (GlutaMAX 1X, Cat\#: 35050061, Gibco ${ }^{\mathrm{TM}}$, Massachusetts, USA). Immediately, the epineurium was removed to reduce fibroblast contamination, and the fascicles and fibers are slightly "teased" under a stereoscopic microscope.

After that, we proceed as described by Rosso et al, (2017) [55]. For the next 10 days, the fibers were cultured at $37^{\circ} \mathrm{C}$ and $5 \% \mathrm{CO}_{2}$ and evaluated by phase-contrast microscopy for $\mathrm{SC}$ and fibroblast (FB) growth. To complete cell-dissociation, on day 11 the fibers were exposed for $24 \mathrm{~h}$ in collagenase medium: DMEM, supplemented with 10\% FBS; PSN 1X and GlutaMAX 1X; collagenase $225 \mu \mathrm{g} / \mathrm{ml}$ and $5 \mathrm{mM} \mathrm{CaCl}$. After $24 \mathrm{~h}$, culture plates were trypsinized and the cell suspension was collected and centrifuged at $250 \mathrm{~g}$ for $3 \mathrm{~min}$ at room temperature (RT). The supernatant was discarded, while the pellet was resuspended in DMEM containing: 10\% FBS; PSN 1X; GlutaMAX 1X; $8 \mu \mathrm{M}$ forskolin (Cat\#: F6886, Sigma-Aldrich ${ }^{\circledR}$, Taufkirchen, Germany) and $20 \mu \mathrm{g} / \mathrm{ml}$ bovine pituitary extract (Cat\#: P1167, Sigma-Aldrich ${ }^{\circledR}$, Taufkirchen, Germany). This cell suspension was seeded and maintained for $48 \mathrm{~h}$ at $37^{\circ} \mathrm{C}$ and $5 \% \mathrm{CO}_{2}$. Immediately afterward, the cultures were trypsinized and the suspension was collected and centrifuged at $250 \mathrm{~g}$ for $3 \mathrm{~min}$ at RT. The pellet was resuspended and seeded on plates previously treated with Poly-D-lysine. Petri dishes were coated with $2 \mathrm{ml}$ of Poly-D-lysine $50 \mu \mathrm{g} / \mathrm{ml}$ (PDL, Cat\#: A3890401, Gibco ${ }^{\mathrm{TM}}$, Massachusetts, USA) for $30 \mathrm{~min}$, followed by two washes with phosphate-buffered saline (PBS, $137 \mathrm{mM} \mathrm{NaCl}, 2.7 \mathrm{mM} \mathrm{KCl}, 10 \mathrm{mM} \mathrm{Na}$ 2HPO4,1.8 mM KH2PO4, pH 7,2-7,6). The 
cell culture was maintained at $37^{\circ} \mathrm{C}$ and $5 \% \mathrm{CO}_{2}$ until sub-confluent growth $(80 \%$ of the whole plate surface), with medium changes every two days.

The greater adhesion of FB to the substrate observed is a property that differentiates them from SCs when both cell types are in culture. Thus, a technique has been developed to separate the two cell types when they are in culture, based on their different adhesion to the substrate. Indeed, the percentage of FB can be decreased by performing the so-called Cold-Jet procedure [56-58]. Briefly, the medium is removed and replaced by ice-cold PBS which is slowly added and rapidly aspirated. The FB, with increased adhesion, remain attached to the Petri dish while the SCs detach. The suspension, thus enriched in SCs, was centrifuged at $250 \mathrm{~g}$ for $3 \mathrm{~min}$. The supernatant was discarded, and the precipitate was resuspended in medium with forskolin and bovine pituitary extract in Petri dishes coated with PDL. These cultures were maintained at $37^{\circ} \mathrm{C}$ and $5 \% \mathrm{CO}_{2}$ until experiments were performed, with medium changes every 2 days. SCs used in the experiments were not further than passage 2 .

\subsection{Curcumin}

Treatment of primary isolated SCs with curcumin was performed by mixing the compound in the culture medium. The starting point was a $10 \mathrm{mM}$ curcumin stock solution (Cat\#: C1386, Sigma Aldrich ${ }^{\circledR}$ Taufkirchen, Germany) diluted in $100 \% \mathrm{EtOH}$, as reported in the literature $[46,59-61]$. This stock solution was stored at $-20^{\circ} \mathrm{C}$ until use. All subsequent dilutions were performed with a culture medium.

\subsection{Determination of curcumin concentration}

We based on previous literature reports to determine the optimal concentration of curcumin to be used $[46,48-52,61,62]$. As a result of the search, the concentration of curcumin was explored between 0.05 and $0.55 \mu \mathrm{M}$.

The viability of the enriched cultures was studied by MTT assay. For this purpose, $1 \times 10^{5}$ cells per well were seeded, in a 96-well plate. $24 \mathrm{~h}$ later, the medium was removed and replaced by medium containing different concentrations of curcumin $(0.05 ; 0.15 ; 0.25$; $0.35 ; 0.45 ; 0.55 \mu \mathrm{M})$. The concentrations were evaluated in triplicate and three independent experiments were carried out. The treatment was conducted for 6 days, with medium changes every 48 hours. On the 6th day of treatment, the medium was removed and replaced by culture medium with the reagent 3-(4,5-Dimethylthiazol-2-yl)-2,5 Diphenyltetrazolium Bromide (MTT) (No. M6494, Invitrogen, Thermo Fisher Scientific, USA), work dilution (WD): $0.5 \mathrm{mg} / \mathrm{ml}$. This pale yellow, water-soluble compound is reduced in the presence of living cells by mitochondrial dehydrogenases, precipitating as formazan (violet-blue crystals, insoluble in water) [63]. The cells were incubated for $2 \mathrm{~h}$ at $37^{\circ} \mathrm{C}$ and $5 \%$ $\mathrm{CO} 2$. Then, the medium was removed and the cells were lysed with DMSO to release and solubilize the formazan crystals followed by absorbance measurements at $570 \mathrm{~nm}$ and 650 $\mathrm{nm}$ (background) in the Varioskan (Varioskan ${ }^{\circledR}$ Flash, Thermo Scientific, Massachusetts, USA). In addition, the effect on the EtOH vehicle was tested separately. Two controls were generated: negative control (without EtOH and curcumin) and EtOH control (with EtOH, without curcumin).

The optical density was calculated by subtracting the values obtained from $650 \mathrm{~nm}$ minus $570 \mathrm{~nm}$ from the average of the values corresponding to the control. The percentages of the controls were calculated taking as reference the average of the values of the negative control; while, for the different concentrations of curcumin tested, the value that corresponded to $100 \%$ viability was the average of the values of the control with $\mathrm{EtOH}$ in the culture medium. 


\subsection{Curcumin Treatment}

After determination of optimal curcumin concentration, determined in 2.4., SC enriched cultures were maintained until growth reached $50-60 \%$ confluence. At this point, the treatment was applied for 6 days under three conditions: negative control (N.ctrl); EtOH control (Et.crtl), and treatment with $0.25 \mu \mathrm{M}$ curcumin in $\mathrm{EtOH}(\mathrm{Et}+\mathrm{Cu})$. All plates were kept at $37^{\circ} \mathrm{C}$ and $5 \% \mathrm{CO}_{2}$ during the course of the treatment and the medium was changed every 48 hours.

\subsection{Immunolabeling in enriched SC cultures}

This qualitative and quantitative assay was performed on 8-field slides, with 500 cells/well seeded in each field. After $24 \mathrm{~h}$, the corresponding treatment/control was applied. For each independent experiment, 4 slides were used: the technique control (without primary antibodies); N.ctrl, Et.ctrl, and Et+Cu. Cells were fixed with $2.5 \%$ paraformaldehyde in PHEM buffer (25 mM HEPES, $60 \mathrm{mM}$ pipes, $10 \mathrm{mM}$ EGTA, $2 \mathrm{mM} \mathrm{MgCl2,} \mathrm{pH}$ $7,2-7,6), 4^{\circ} \mathrm{C}$, for $20 \mathrm{~min}$ followed by permeabilization with $0.1 \%$ Triton-X-100 in PHEM buffer for $30 \mathrm{~min}$. Then, the cells were then incubated with the specific antibodies in incubation buffer (IB: glycine $100 \mathrm{mM}, 0.1 \% \mathrm{BSA}$ in PHEM), for $24 \mathrm{~h}$ a $4^{\circ} \mathrm{C}$.

The specific antibodies used were: anti-PMP22 (Cat\# ab61220, RRID: AB_944897, Abcam, Cambridge, UK) WD: 1:100; anti-HSF1 (Cat\# SMC-476, RRID: AB_2702279, StressMarq Biosciences, Victoria, Canada) WD: 1:200; anti-Hsp25/27 (Cat\# SMC-114, RRID: AB_2120775, StressMarq Biosciences, Victoria, Canada) WD: 1:200; anti-HDAC6 (Cat\# ab56926, RRID: AB_941882, Abcam, Cambridge, UK) WD 1:50 and anti-ribosomal proteins, WD 1:200. After $24 \mathrm{~h}$, IB was washed at RT and then the nonspecific binding sites of the secondary antibodies were blocked using IB with 5\% normal goat serum (NGS) for $30 \mathrm{~min}, 37^{\circ} \mathrm{C}$. Incubation with the secondary antibodies, for $45 \mathrm{~min}$ at RT and in the dark, was preceded by washes in IB at RT. The secondary antibodies and probe used were: Goat Anti-Mouse IgG (H+L) Highly Cross-adsorbed Antibody, Alexa Fluor 488 Conjugated (Cat\# A-11029, RRID: AB_138404, Molecular Probes, Eugene, USA) WD: 1:1000, Goat Anti-Rat IgG (H+L) Antibody, Alexa Fluor 555 Conjugated (Cat\# A-21434, RRID: AB_141733, Molecular Probes, Eugene, USA) WD: 1:1000; Goat anti-Rabbit IgG (H+L) Cross-Adsorbed Secondary Antibody, Cyanine5 (Cat\# A10523, RRID: AB_2534032, Thermo Fisher Scientific, Massachusetts, USA) WD: 1:1000 y DAPI (4',6-Diamidino-2-Phenylindole, Dihydrochloride) (Cat\# D1306, RRID: AB_2629482, Thermo Fisher Scientific, Massachusetts, USA) WD: 1:1000.

Washes were then performed with IB and subsequently with PHEM buffer. After that, the coverslips were removed and mounted with Prolong ${ }^{\mathrm{TM}}$ Diamond Antifade (Cat\#: P36970, Invitrogen ${ }^{\mathrm{TM}}$, Massachusetts, USA).

\subsection{Confocal microscopy}

Cell culture growth and morphology of cell types were performed on a Nikon Diaphot 300 inverted light microscope.

Immunostaining was visualized with a Zeiss LSM 800 confocal microscope. At the beginning of the confocal session, the maximum laser photomultiplier levels and voltage were set with the negative controls for each sample, until a few bright non-specific signals started to appear. Then, all images containing specific antibodies were taken under the same conditions, in the same section.

\subsection{Fluorescence image analysis}

The images obtained were analyzed with ImageJ software (version 1.53b, RRID: SCR_003070). Quantification of the intensity of the differently labeled proteins was performed by discriminating the nuclear compartment from the cytoplasmic compartment. For the nucleus, binary plane-to-plane masks were established, and based on these, intensity values per unit area were obtained. To obtain the cytoplasm values, the total cell, and 
nucleus masks were subtracted, resulting in the corresponding cytoplasm mask for each cell. For each of the conditions, 100 cells per genotype were evaluated.

\subsection{Statistical analysis}

The normality of the data obtained was evaluated by the Shapiro-Wilk test. The comparison between controls and the effects of the same concentration of curcumin between genotypes by MTT was performed using the nonparametric Mann-Whitney U signedrank test. In addition, for the study of the different curcumin concentrations tested, the non-parametric Kruskal-Wallis test was applied, together with the Dunn's multiple comparison test, evaluating the differences concerning to Et.crtl.

For the comparison between N.ctrl, Et.ctrl, and $\mathrm{Et}+\mathrm{Cu}$ in each genotype, one-way ANOVA ( $\mathrm{FDFn}_{\mathrm{DF}}$, DFd=297, $\mathrm{p}$-value) or the Kruskal-Wallis ( $\mathrm{H}$, p-value) test were performed. Multiple comparisons were performed to understand the variations between N.ctrl vs Et.ctrl and Et.ctrl vs Et+Cu treatment. Dunnett's test for one-way ANOVA (p-value, [95 CI of Dif]) and Dunn's test for Kruskal-Wallis (p-value). In addition, the comparison of each treatment between genotypes was analyzed by unpaired Student's $t$-test ( $\mathrm{p}$-value, $\mathrm{t}$, $\mathrm{df}=198$ ) or Mann-Whitney U signed-rank test ( $\mathrm{p}$-value, $\mathrm{U}$ ). All tests were applied using a two-tailed distribution and the results were considered significant at an alpha level of 0.05. Statistical analysis was performed with GraphPad Prism $8 \circledR$ software (GraphPad Prism, RRID: SCR_002798).
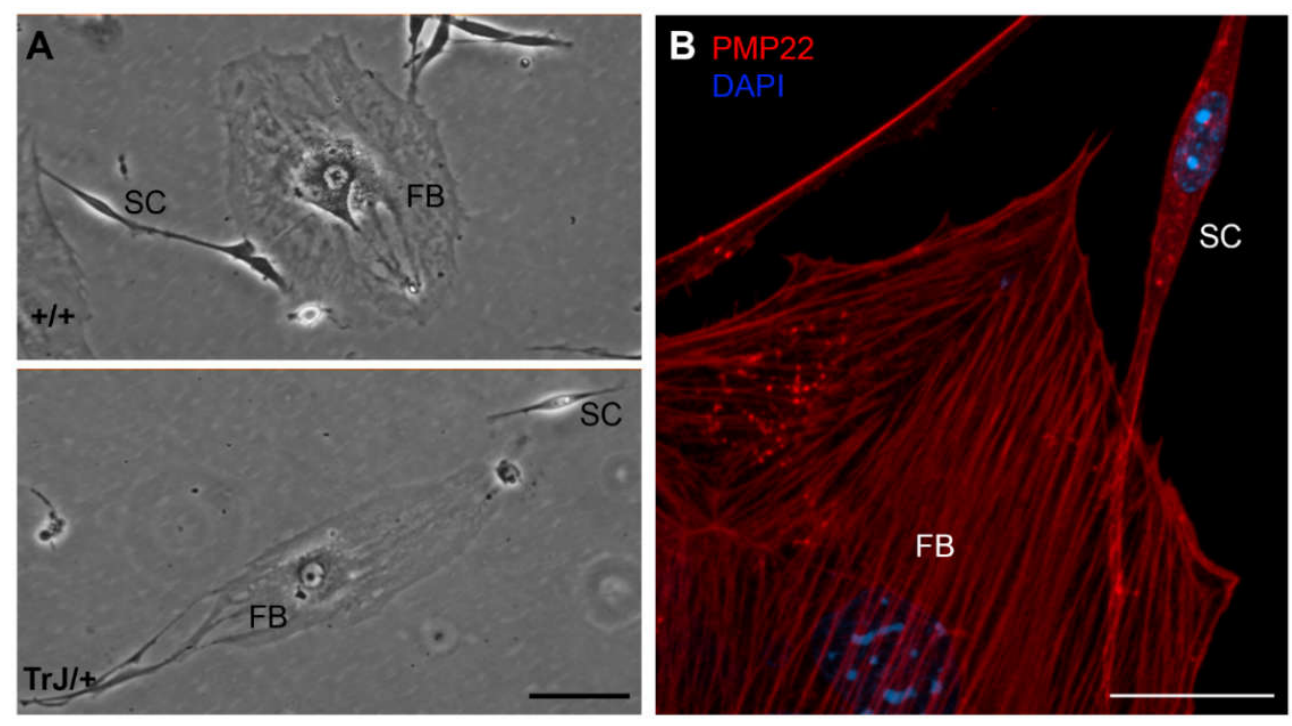

Figure 1. Morphology of different cell types in enriched SC cultures. (A) In both +/+ and TrJ/+ genotypes, fibroblasts (FB) and Schwann cells (SC) show morphological differences. FB show heterogeneous flattened shape with abundant cytoplasm and a large nucleus easily distinguishable under light microscopy. SCs show typically bipolar shape with lateral extensions and a smaller size compared to FBs. (B) Confocal microscopy image showing PMP22 (red) and nuclear labeling counterstain (DAPI, blue). Scale in A = $250 \mu \mathrm{m}$. Scale in $B=20 \mu \mathrm{m}$.

\section{Results}

\subsection{Morphological differences between FBs and SCs}

The identification of both cell types was based on their morphological differences, distinguishable under the bright field microscope. SCs have a fusiform bipolar shape, with a central zone from which a prolongation extends to each end (Fig. 1, SC). The extensions are of variable length, but common to all SCs is the presence of one extension longer than the other. SCs are easily distinguishable from FBs as the latter have a heterogeneous, mainly stellate shape (Fig. 1, FB). The spreading area as well as major and minor axis length values of both cell types were measured and shown in Table 1. Comparison between total spreading areas reveal that one FB possess an area equivalent to almost 30 
times bigger than a SC. These morphological and size differences were visualized in $+/+$ and TrJ/+ cultures (Fig. 1A) and immunolabeled confocal images (Fig. 1B). Morphological comparisons of different cell types, between $+/+$ and $\operatorname{Tr} J /$ genotypes, yielded no significant differences (data not shown).

Figure 2. Enriched SC - FB cultures obtained by different protocols. Images of mixed primary culture obtained from the "collagenase-

\section{“Collagenase-trypsin" Method}
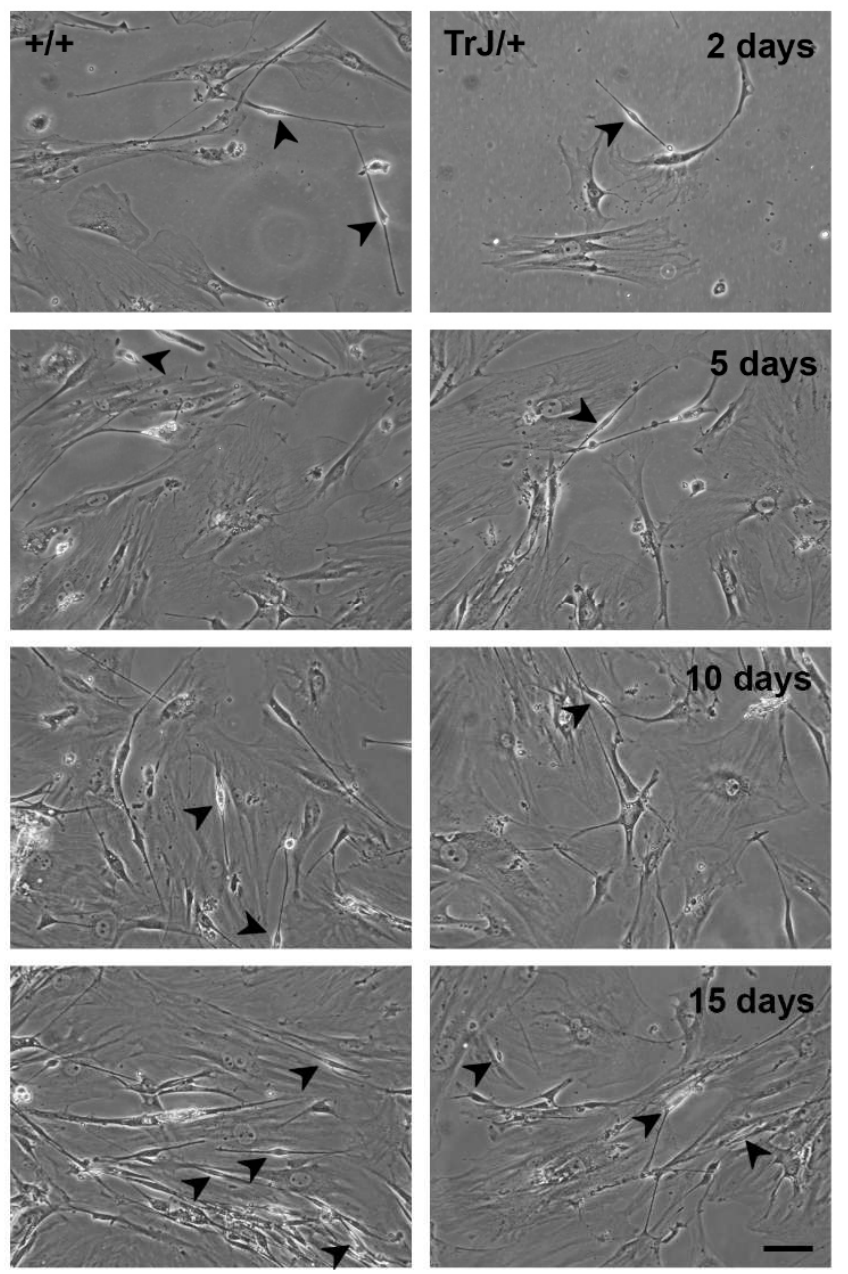

\section{Modified Rosso et al. Method}
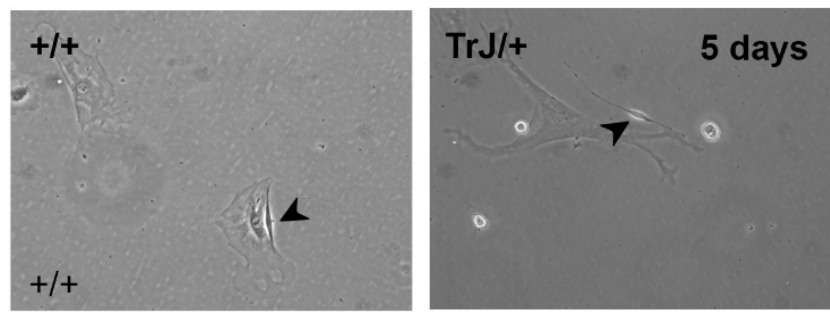
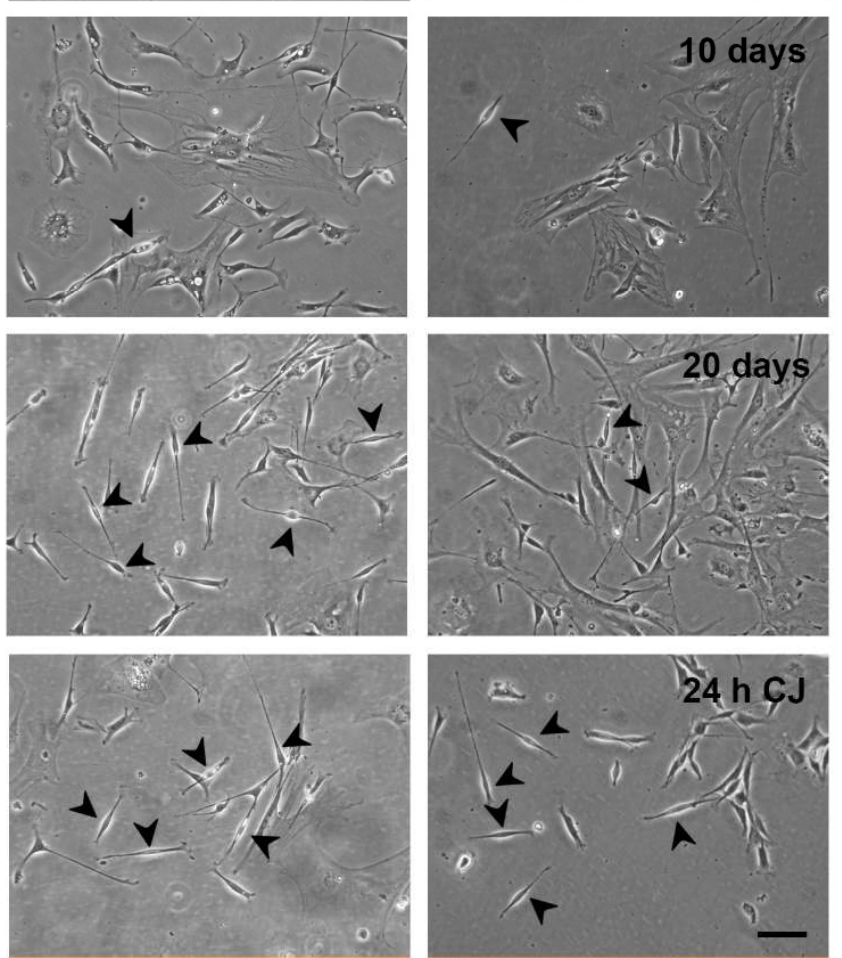

trypsin" protocol are visualized in the left panels in the $+/+$ and $\operatorname{Tr} / /+$ cultures. This protocol allows obtaining in 8 days a large number of cell, but the SC/FB ratio is rather low, as observed after 15 days of seeding. Images of the mixed primary culture obtained with the modified protocol of Rosso et al., 2017 [55] in +/+ and TrJ/+ are displayed in the right panels. This method requires more time to obtain a large number of cell volumes. The epineurium removal and enrichment by Cold-Jet (CJ) allows us to obtain a higher SC/FB ratio, compared to the collagenase-trypsin protocol. Arrowheads point to SCs. Scale $=250 \mu \mathrm{m}$ for all panels

Table 1. Morphometric parameters of SC and FB. Evaluation of the area, major and minor length of Schwann cells (SC), and fibroblasts (FB) of $+/+$ and $\mathrm{TrJ} /+$ cultures. Measurements expressed in Mean \pm SEM.

\begin{tabular}{cccc}
\hline Cell type & Area $\left(\boldsymbol{\mu m}^{2}\right)$ & Major length $(\mu \mathrm{m})$ & Minor length $(\boldsymbol{\mu m})$ \\
\hline FB & $180,554 \pm 27,043$ & $615 \pm 61$ & $275 \pm 41$ \\
SC & $6,062 \pm 699$ & $456 \pm 51$ & $30 \pm 3$ \\
\hline
\end{tabular}


A

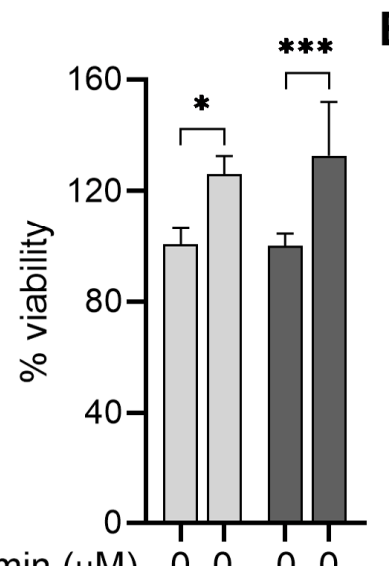

Curcumin $(\mu \mathrm{M}) \quad 0 \quad 0 \quad 00$ $\mathrm{EtOH}$
B

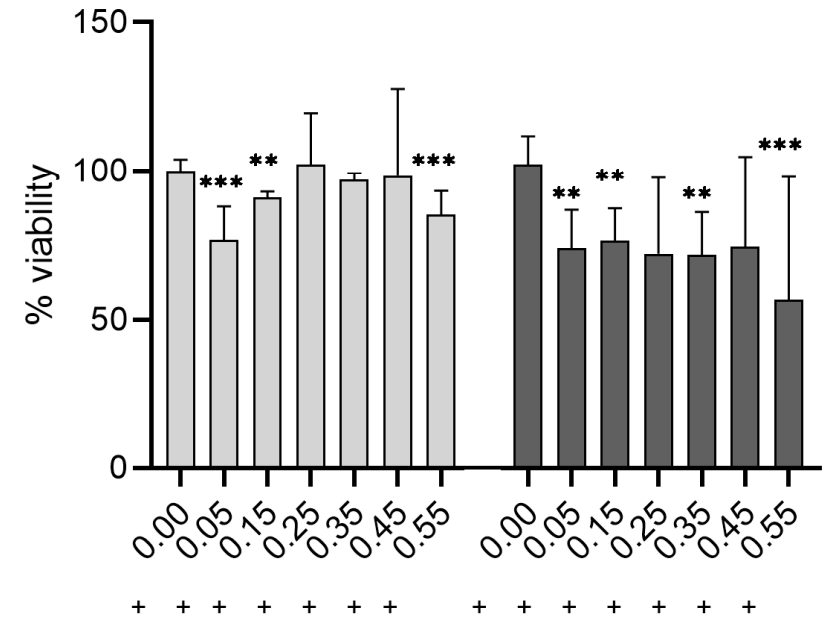

C

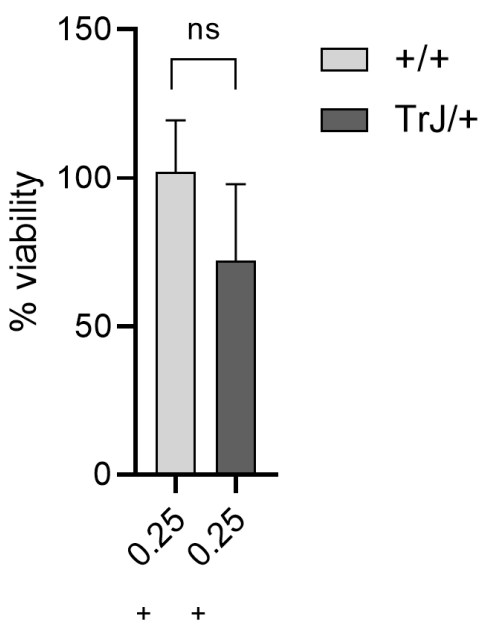

Figure 3. Cell viability by MTT assay. Enriched SCs cultures +/+ and TrJ/+ were treated for 6 days with different concentrations of curcumin (added to the culture medium) in addition to the evaluation of N.ctrl (without curcumin and EtOH) and Et.ctrl (without curcumin, with EtOH, $0.43 \mathrm{mM}$ ). (A) Control comparison within each genotype show a significant increase in viability of the Et.ctrl compared to N.ctrl. Comparison +/+ vs. TrJ/+ no significant differences (data not showing). (B) Comparison of the different curcumin concentrations to Et.ctrl in +/+ and $\operatorname{Tr} J /+$. (C) Comparison +/+ vs. $\operatorname{TrJ} /+$ of the lowest concentration $(0.25 \mu \mathrm{M})$ without differences with respect to Et.ctrl. obtained in (B) for both genotypes. The data, expressed as median \pm SIR, were analyzed in (A) and (C) by MannWhitney $U$ signed-rank test and in (B) by the Kruskal-Wallis test. ${ }^{*} \mathrm{p}<0.05^{* *} \mathrm{p}<0.002$; ${ }^{* *} \mathrm{p}<0.0002$. SIR: semi interquartile range.

\subsection{Obtaining of cultures enriched in $+/+$ and $T r J /+S C s$}

The mixed cultures obtained from the application of two different protocols are visualized in Figure 2. The "collagenase-trypsin" method allowed to obtaining a large cell volume after 10 days, although it yields a low SC/FB ratio (Fig. 2, left panels). On the other hand, the modified method described in Rosso et al. 2017 [55] showed a better SC/FB ratio, although it takes longer (21 days) (Fig. 2, right panels).

Although it presents greater complexity, the second protocol contains two key steps where its efficiency lies for yielding a greater number of SCs: namely the initial step which requires an exhaustive removal the epineurium, and the last stage of the protocol where enrichment of SCs takes place after using the Cold-Jet technique. Taking into account these advantages, this last protocol was selected over the "collagenase-trypsin" method to continue with the experiments.

\subsection{Determination of suitable curcumin concentration to be used in enriched +/+ and TrJ/+ SC cultures.}

The determination of the lowest curcumin concentration, with no effect on the SC culture viability (i.e., no difference from the Et.ctrl) was evaluated by MTT assay (Fig. 3).

The effect of EtOH compared to untreated cultures (Fig. 3A), showed in +/+ SCs an increase in viability by $42 \%(\mathrm{p}=0.0275, \mathrm{U}=218)$, while in SCs $\mathrm{TrJ} /+$ an increase of $33 \%$ $(\mathrm{p}=0.0002, \mathrm{U}=163)$. In addition, the comparison between $+/+$ and $\mathrm{Tr} \mathrm{J} /+$ of $\mathrm{EtOH}$ effects, revealed the absence of significant differences, suggesting that the EtOH effect is similar in both genotypes.

The comparison between $\mathrm{Et}+\mathrm{Cu}$ concentrations vs Et.ctrl (Fig. 3B) showed a decrease in $+/+$ SCs viability at $0.05,0.15$, and $0.55 \mu \mathrm{M}$ concentrations $(\mathrm{H}=61.76, \mathrm{p}<0.0001 ; 0.05 \mu \mathrm{M}$ : $\mathrm{p}=0.0003 ; 0.15 \mu \mathrm{M}: \mathrm{p}=0.0015 ; 0.55 \mu \mathrm{M}: \mathrm{p}=0.0001$ ); while at $0.25,0.35$, and $0.45 \mu \mathrm{M}$ we did not observe differences from the Et.ctrl. The results in $\mathrm{TrJ} /+\mathrm{SC}$ s showed a decrease in viability at $0.05,0.15,0.35$ and $0.55 \mu \mathrm{M}$ concentrations $(\mathrm{H}=23.03, \mathrm{p}=0,0008 ; 0.05 \mu \mathrm{M}$ : $\mathrm{p}=0.0029 ; 0.15 \mu \mathrm{M}: \mathrm{p}=0.0036 ; 0.35 \mu \mathrm{M}: \mathrm{p}=0.0097 ; 0.055 \mu \mathrm{M}: \mathrm{p}=0.0001)$, while 0.25 and 0.45 $\mu \mathrm{M}$ had no difference with respect to Et.ctrl. 
In summary, these results indicate that $0.25 \mu \mathrm{M}$ curcumin was the lowest concentration showing no significant differences from the vehicle control in both genotypes and also had no significant differences between genotypes $(p=0.0557, U=319)$ (Fig. 3C).
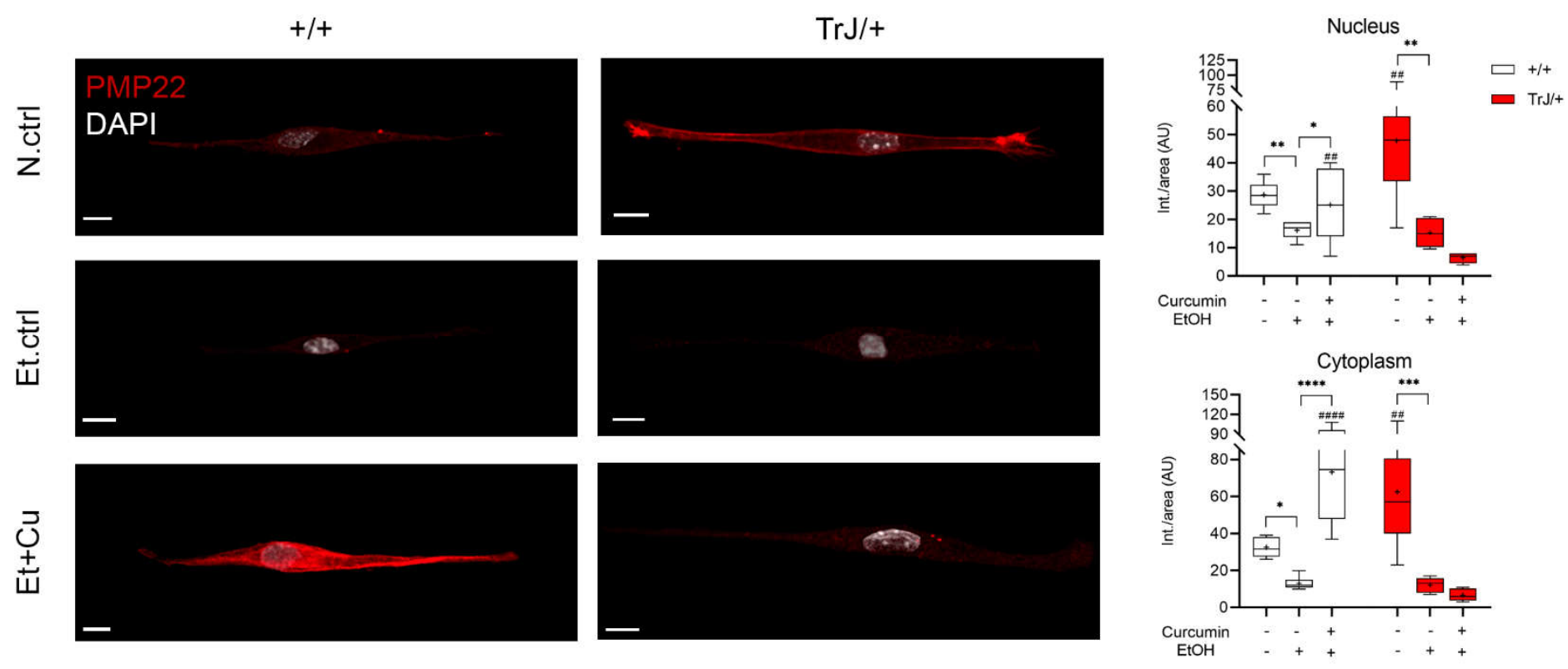

Figure 4. Modulation of PMP22 expression in +/+ and TrJ/+ SCs enriched cultures. Confocal microscopy images of +/+ and TrJ/+ SCs N.Ctrl, Et.ctrl $(0.43 \mathrm{mM} \mathrm{EtOH})$ and $\mathrm{Et}+\mathrm{Cu}(0.25 \mu \mathrm{M}$ curcumin $+0.43 \mathrm{mM} \mathrm{EtOH})$ were quantified at the nuclear and cytoplasmic level. Et.ctrl vs. N.ctrl, had a nuclear decrease in PMP22 expression in +/+ SC, while in TrJ/+ SC it is observed in both compartments. On the other hand, $\mathrm{Et}+\mathrm{Cu}$ treatment vs. Et.ctrl, showed an increase compared to both cell compartments, only for the $+/+$ genotype. In turn, the comparison +/+ vs. TrJ/+ SCs of the same condition revealed differences in both compartments, in N.ctrl and Et+Cu treatment. Within each genotype: ${ }^{*} \mathrm{p}<0.033 ;{ }^{* *} \mathrm{p}<0.002 ;{ }^{* * *} \mathrm{p}<0.0002 ;{ }^{* * * *} \mathrm{p}<0.0001$. Same treatment between $+/+$ and $\mathrm{Tr} \mathrm{J} /+$ : \#\# $\mathrm{p}<0.002$; \#\#\# $\mathrm{p}<0.0001$. The mean is shown as " + ". Scale $=10 \mu \mathrm{m}$ for all panels. $\mathrm{N}=100$ cells in average per condition for each genotype.

\subsection{Effect of curcumin treatment on $S C+/+$ and $T r J /+$ enriched cultures}

\subsubsection{Alterations in PMP22 expression}

The study of PMP22 expression in +/+ and TrJ/+ SCs was analyzed by confocal microscopy (Fig. 4). At the nuclear level, for both +/+ and TrJ/+ SCs, one-way ANOVA analysis reported significant differences between N.ctrl, Et.ctrl and Et+Cu treatment (+/+: $\mathrm{F}=16.14, \mathrm{p}=0.0062) ; \mathrm{TrJ} /+\mathrm{F}=2.425, \mathrm{p}=0.0004)$. In +/+ SCs, there is a decrease of PMP22 expression in $0.43 \mathrm{mM}$ Et.ctrl, compared to N.ctrl $(\mathrm{p}=0.0014,[-21.12,-3.875])$ and an increase in the $0.25 \mu \mathrm{M}$ curcumin, compared to Et.ctrl ( $\mathrm{p}=0.0292,[-17.07 ;-0.8420])$. For TrJ/+ SCs, was reported only a decrease in PMP22 expression in Et.ctrl, compared to N.ctrl ( $p=0.0292$, $[-53.08 ;-12.10])$. At the cytoplasmic level, significant differences were reported between N.ctrl, Et.ctrl and Et+Cu treatments (+/+: H=31.57, $\mathrm{p}<0.0001)$; TrJ/+: $\mathrm{F}=4.864, \mathrm{p}<0.0001)$ for both +/+ and TrJ/+ SC. In +/+ SCs, a decrease in PMP22 expression with Et.ctrl, compared to N.ctrl $(\mathrm{p}=0.0343)$, and an increase in $\mathrm{Et}+\mathrm{Cu}$ treatment, compared to Et.ctrl $(\mathrm{p}<0.0001)$; while in $\mathrm{Tr} J /+$ SC a significant decrease in expression was observed with Et.ctrl, compared to the N.ctrl ( $\mathrm{p}=0.006,[-77.22 ;-23.58])$.

Variations in PMP22 expression levels were also evaluated in different conditions comparing SCs of +/+ and TrJ/+. In nuclear and cytoplasmic domains, N.ctrl showed higher PMP22 expression in TrJ/+ (nucleus: $\mathrm{p}=0.0097, \mathrm{t}=2.910$; cytoplasm: $\mathrm{p}=0.0020$, $\mathrm{t}=3.519$ ), while in the Et+Cu treatment, presented higher PMP22 expression in +/+ SC (nucleus: $\mathrm{p}=0.0096, \mathrm{t}=2.964$; cytoplasm: $\mathrm{p}<0.0001$, $\mathrm{t}=6.549$ ).

The data indicate an increase in PMP22 expression with curcumin treatment in $+/+$ SC, compared to Et.ctrl in nucleus and cytoplasm, but no changes are visualized in $\operatorname{TrJ} /+$ 
SCs. In addition, N.ctrl showed increased expression in $\operatorname{Tr} \mathrm{J} /+$, compared to $+/+$, whereas $\mathrm{Et}+\mathrm{Cu}$ treatment showed increased PMP22 expression in $+/+\mathrm{SC}$, in both compartments.

A - HSF1
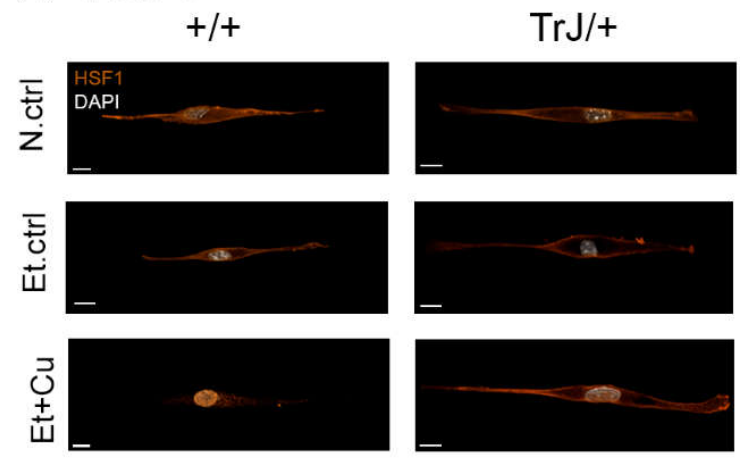

\section{B - Hsp27}

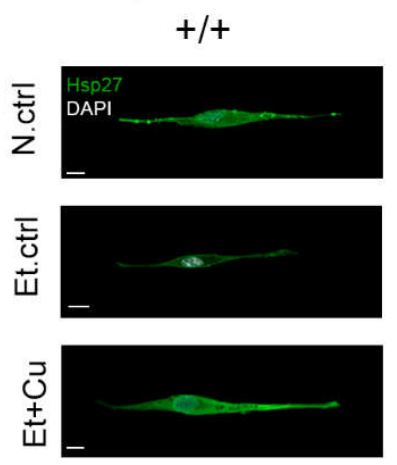

\section{$\operatorname{Tr} \mathrm{J} /+$}

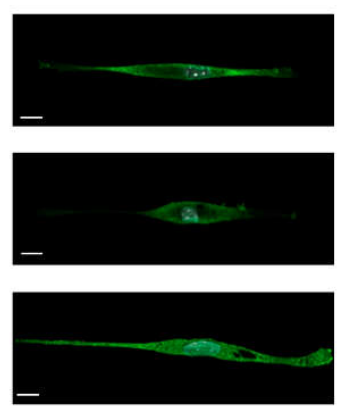

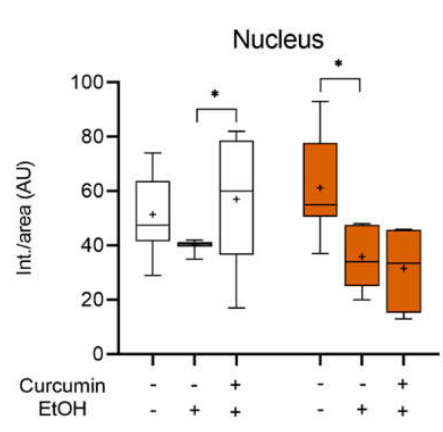
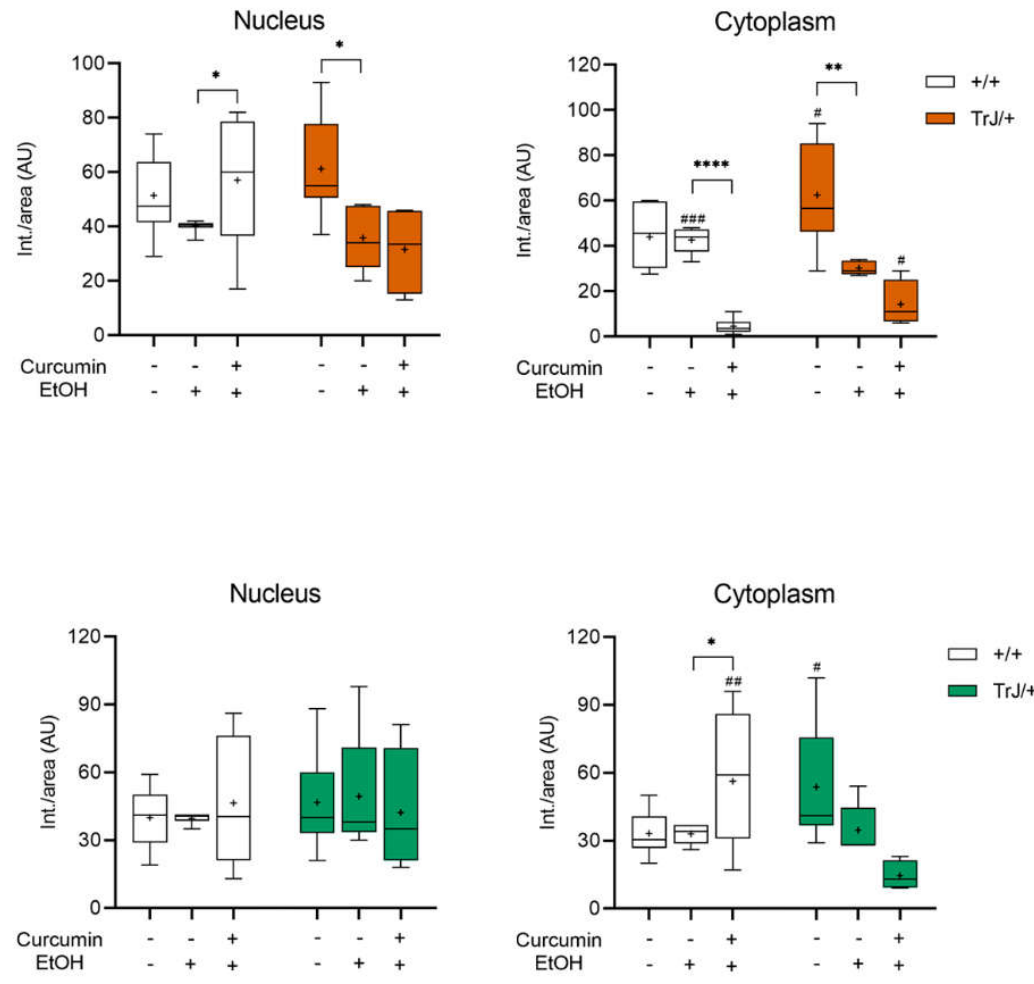

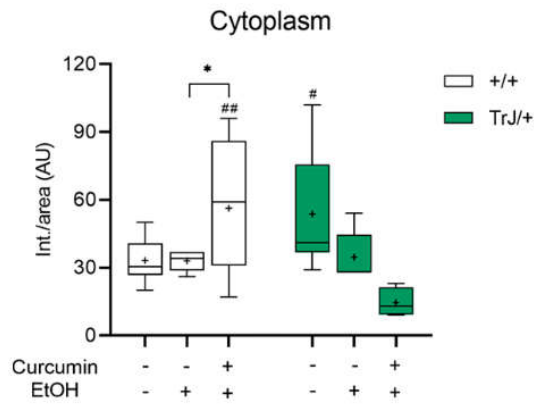

Figure 5. Modulation of HSF1 and Hsp27 expression levels in +/+ and TrJ/+ SCs enriched cultures. Images obtained by confocal microscopy of +/+ and TrJ/+ SC N.ctrl, E.ctrl, and Et+Cu were quantified in the nucleus and cytoplasm. (A) HSF1 expressión. Et.ctrl vs N.ctrl had a decrease only in TrJ/+ SC in both compartments. Et+Cu treatment vs. Et.ctrl showed a nuclear increase and a cytoplasmic decrease only in +/+ SCs. In turn, the comparison +/+ vs. TrJ/+ SCs of the same condition revealed only cytoplasmic differences in Et.ctrl and Et+Cu. (B) Hsp27 expression. No differences were observed between Et.ctrl vs. N.ctrl, in both genotypes or both compartments. A comparison $+/+$ vs. TrJ/+ SCs of the same condition revealed cytoplasmic differences in N.ctrl and Et.ctrl. Within each genotype: ${ }^{*} \mathrm{p}<0.033 ;{ }^{* *} \mathrm{p}<0.002 ;{ }^{* * *} \mathrm{p}<0.0002 ;{ }^{* * * *} \mathrm{p}<0.0001$. Same treatment between $+/+$ and $\mathrm{TrJ} /+$ : \#\# $\mathrm{p}<0.002$; \#\#\#\# $\mathrm{p}<0.0001$. The mean is shown as " + ". Scale $=10 \mu \mathrm{m}$ for all panels. $\mathrm{N}=100$ cells in average per condition for each genotype.

\subsubsection{Effect of curcumin on heat shock response: expression of HSF1 and Hsp27}

The study of HSF1 and Hsp27 expression, as markers of stress response, in +/+ and $\mathrm{TrJ} /+$ SC enriched cultures, modulated by the curcumin treatment was analyzed by confocal microscopy (Fig. 5). Nuclear HSF1 in Fig. 5A show significant differences between N.ctrl, Et.ctrl and Et+Cu (+/+: H=7.046, p=0.0295; TrJ/+: F=0.28, p=0.0072). In +/+ SCs an increase of HSF1 intensity was observed after Et+Cu treatment, compared to Et.ctrl $(\mathrm{p}=0.0210)$. However, we observed a decrease of HSF1 with Et.ctrl compared to N.ctrl $(\mathrm{p}=0.0205,[-46.82 ;-3.976])$ in $\mathrm{Tr} J /+\mathrm{SC}$. No difference was observed with respct to $\mathrm{Et}+\mathrm{Cu}$ treatment. In cytoplasmic domains, HSF1 showed significant differences between N.ctrl., Et.ctrl and $\mathrm{Et}+\mathrm{Cu}(+/+: \mathrm{F}=19.44, \mathrm{p}<0.0001 ; \mathrm{TrJ} /+\mathrm{F}=3.75, \mathrm{p}=0.0004)$; in +/+ SC a decrease of HSF1 with $\mathrm{Et}+\mathrm{Cu}$ treatment compared to Et.ctrl was evident ( $<<0.0001,[38.84 ; 45.36])$. Meanwhile, in TrJ/+ SC a decrease of HSF1 with Et.ctrl, compared to N.ctrl was observed $(p=0.0068,[-55.08 ;-9.316])$. Differences between conditions in both genotypes revealed significant differences only at the cytoplasmic level. Both N.ctrl and Et+Cu treatment showed higher expression of HSF1 in TrJ/+ (N.ctrl: $\mathrm{p}=0.0374, \mathrm{t}=2.247 ; \mathrm{Et}+\mathrm{Cu}$ treatment: $\mathrm{p}=0.0134, \mathrm{U}=6.50)$; while Et.ctrl showed higher expression in $+/+(\mathrm{p}=0.0004, \mathrm{t}=4.719)$. 


\section{A - HDAC6}
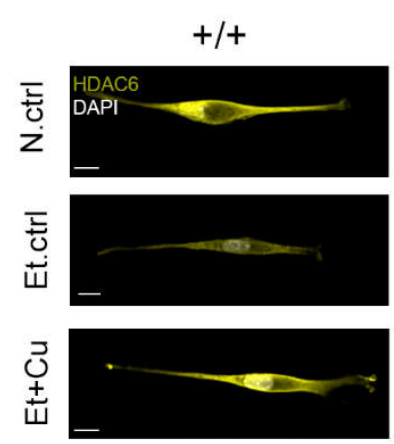

\section{B - Ribosomes}

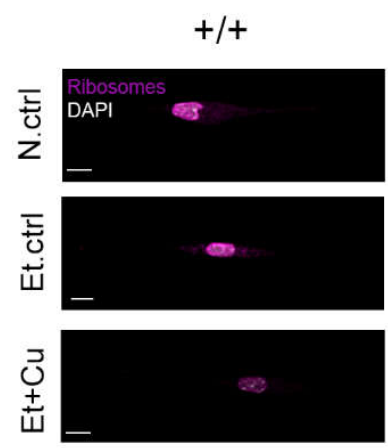

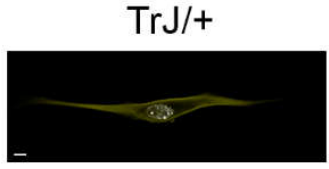
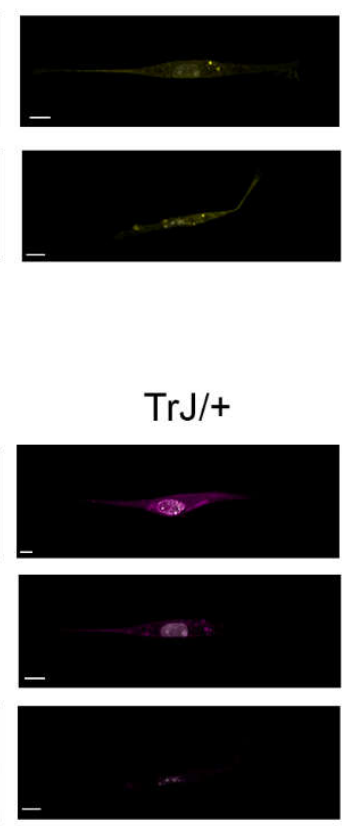
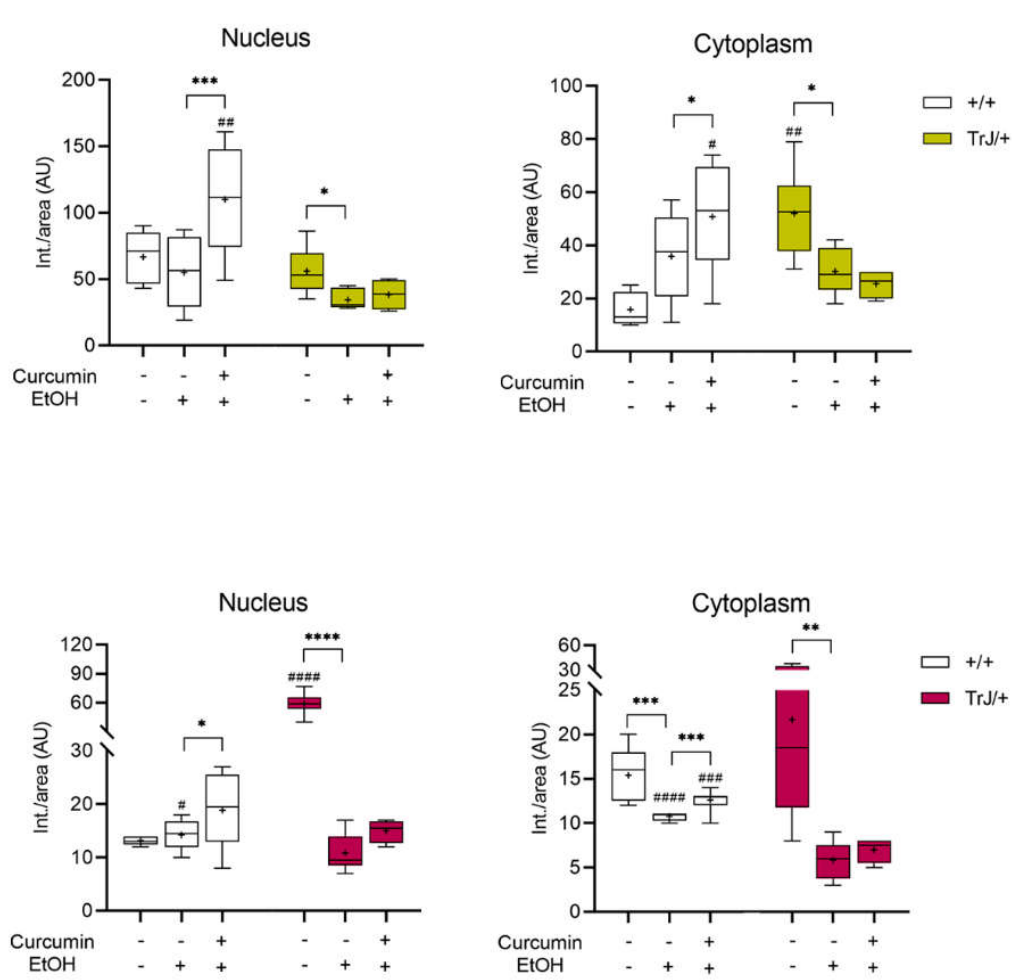

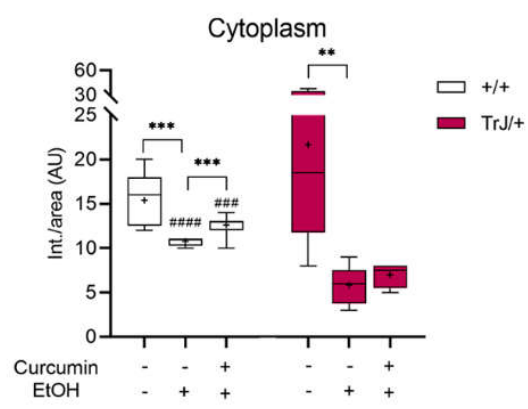

Figure 6. Modulation of HDAC6 and ribosome expression in $+/+$ and TrJ/+ SC enriched cultures. Images obtained by confocal microscopy of $+/+$ and $\mathrm{TrJ} /+$ SC in N.ctrl, E.ctrl, and Et+Cu were quantified in the nucleus and cytoplasm. (A) HDAC6 expression. Et.ctrl vs N.ctrl showed a decrease only in TrJ/+ SCs in both compartments. Et+Cu vs Et.ctrl showed an increase in $+/+$ SCs in both compartments. Conversely, the same condition between $+/+$ and $\mathrm{TrJ} /+\mathrm{SC}$ revealed nuclear differences only with Et+Cu. At the cytoplasmic level, differences were observed with the N.ctrl and Et+Cu. (B) Ribosome's expression. Et.ctrl vs N.ctrl, showed a nuclear decrease only in $\operatorname{TrJ} /+$, while the cytoplasmic decrease occurred in both genotypes. Et+Cu vs Et.ctrl showed an increased expression in +/+ SCs in both compartments. +/+ vs. TrJ/+ SCs revealed nuclear differences with the N.ctrl and the Et.ctrl, and cytoplasmic differences with Et.ctrl and $\mathrm{Et}+\mathrm{Cu}$ treatment. Within each genotype: ${ }^{*} \mathrm{p}<0.033 ;{ }^{* *} \mathrm{p}<0.002 ;{ }^{* * *} \mathrm{p}<0.0002 ;{ }^{* * *} \mathrm{p}<0.0001$. Same treatment, +/+ vs. TrJ/+; \#p<0.033; \#\# $<<0.0002 ; \# \# \#$ p $<0.0001$. The mean is shown as " + ". Scale $=10 \mu \mathrm{m}$ for all panels. N=100 cells in average per condition for each genotype.

On the other hand, Hsp27 showed significant differences in the three studied conditions only at the cytoplasmic level (+/+: $\mathrm{F}=15.88, \mathrm{p}=0.0049$; $\mathrm{TrJ} /+$ : $\mathrm{H}=11.79, \mathrm{p}=0.0002)$, but differences were only observed in $+/+\mathrm{SC}$, giving an increase in Hsp27 expression with curcumin treatment compared to the Et.ctrl ( $\mathrm{p}=0.0101$, [-41.25; -5.288]). Furthermore, differences between $+/+$ and $\operatorname{TrJ} /++$ in the different conditions are observed only at the cytoplasmic level: while Hsp27 expression of the N.ctrl was is higher in $\operatorname{Tr} \mathrm{J} /+\mathrm{SC}(\mathrm{p}=0.0230$, $\mathrm{t}=2.485)$, curcumin treatment resulted higher in $+/+\mathrm{SC}(\mathrm{p}=0.0009, \mathrm{t}=2.950)$ (Fig. 5B).

The data indicate a nuclear increase and a cytoplasmic decrease in HSF1 expression, along with a cytoplasmic increase in Hsp27, with curcumin treatment in +/+ SC, compared to the E.ctrl, but no changes are visualized in TrJ/+ SC. Furthermore, at the cytoplasmic level, increased expression of HSF1 and Hsp27 in TrJ/+ SC was observed in N.ctrl, increased expression of HSF1 in +/+ SC in Et.ctrl and increased expression of HSF1 in TrJ/+ and Hsp27 in +/+ SC in Et+Cu. 
The expression of HDAC6 and ribosomes, as autophagy/mTOR pathway markers, in $\mathrm{SC}+/+$ and $\mathrm{TrJ} /+$ cultures in response to curcumin treatment was analyzed by confocal microscopy (Fig. 6).

In all compartments, HDAC6 showed significant differences between N.ctrl, Et.ctrl and $\mathrm{Et}+\mathrm{Cu}$ (nucleus: +/+: $\mathrm{F}=3.676, \mathrm{p}=0.0002 ; \mathrm{TrJ} /+: \mathrm{H}=6.79, \mathrm{p}=0.0243$; cytoplasm: +/+: $\mathrm{F}=2.92$, $\mathrm{p}=0.0006$; $\operatorname{TrJ} /+\mathrm{F}=1.57, \mathrm{p}=0.0066$ ). Moreover, in both nuclear and cytoplasmic compartments the same behavior occurred: in +/+ SC an increase of HDAC6 imprinting was observed with $\mathrm{Et}+\mathrm{Cu}$ treatment, with respect to the Et.ctrl (nucleus: $\mathrm{p}=0.0001,[-82.79$; -27.14]; cytoplasm: $\mathrm{p}=0.0431$ [-29.42; -0.418]); while in TrJ/+ SC a decrease in HDAC6 expression was observed in the Et.ctrl, respect to N.ctrl (nucleus: $p=0.0235$; cytoplasm: $\mathrm{p}=0.0138$ [-38.95; -4.713]). In nuclear domains, higher HDAC6 expression was observed only in $\mathrm{TrJ} /+\mathrm{SC}$ with $\mathrm{Et}+\mathrm{Cu}$ treatment $(\mathrm{p}=0.0140, \mathrm{t}=3.655)$, and at the cytoplasmic level differences in expression were seen with the N.ctrl $(\mathrm{p}=0.0013, \mathrm{t}=4.5854)$ and with Et+Cu treatment ( $\mathrm{p}=0.0165, \mathrm{t}=2.597$ ), being in both cases higher expression in $+/+\mathrm{SC}$ (Fig. 6A).

Ribosome expression levels showed differences in all compartments between N.ctrl, Et.ctrl and Et+Cu (nucleus: +/+: F=12.75, p=0.0190; TrJ/+: F=1.482, p<0.0001; cytoplasm: +/+: $\mathrm{H}=21.02$, $\mathrm{p}<0.0001 ; \mathrm{TrJ} /+\mathrm{F}=4.01, \mathrm{p}=0.0057)$. In the nucleus, ribosome expression showed differences in $+/+\mathrm{SC}$, there being an increase in expression with Et+Cu treatment, with respect to the Et.ctrl ( $\mathrm{p}=0.0323$ [-8.847; -0.353]), while in $\mathrm{Tr}] /+\mathrm{SC}$ the difference translated into a decrease in ribosomal expression in the Et.ctrl, compared to N.ctrl ( $p<0.0001,[-59.42$; -37.25]). In SC +/+ cytoplasm, a decrease in ribosome expression was observed with Et.ctrl, compared to N.ctrl ( $p=0.0001)$, and an increase with Et+Cu, compared to Et.ctrl ( $p=0.0003)$. In the cytoplasm of TrJ/+ SC only a significant decrease was observed with Et.ctrl $(p=0.0055,[-26.59 ;-5.08])$, as was $+/+$ SC. The evaluation of differential expression within the same condition, for the $+/+$ and $\operatorname{TrJ} /+$ genotypes, showed at SC nuclear level a higher basal culture conditions expression of ribosomes in $\operatorname{Tr} J /+(\mathrm{p}<0.0001, \mathrm{t}=8.610)$ and a higher expression in $+/+$ SC Et.ctrl $(p=0.0329$, $t=2.335)$. At the cytoplasmic level, the highest ribosomal expression was observed in $+/+\mathrm{SC}$ with both Et.ctrl $(\mathrm{p}<0.0001, \mathrm{U}=0)$ and Et+Cu treatment ( $\mathrm{p}=0.0002, \mathrm{U}=0)$ (Fig. 6B).

The data indicate a nuclear and cytoplasmic increase in HDAC6 and ribosome expression with curcumin treatment in +/+ SC compared to the Et.ctrll; but no changes are visualized in TrJ/+ SC. In addition, for HDAC6 a cytoplasmic increase was observed in N.crtl in TrJ/+ SC and an increase in both compartments in +/+ SC with Et+Cu treatment. In the case of ribosomes, N.crtl indicated increased nuclear expression in TrJ/+ SC, E.crtl increased expression in +/+ SC in both compartments and $\mathrm{Et}+\mathrm{Cu}$ increased cytoplasmic expression in $+/+$ SC.

\section{Discussion}

PMP22 expression has been studied both in vivo, using different animal models $[4,10,33,64-67]$, and in vitro in SC cultures $[9,48,68]$, respectively. These approaches denote different but complementary physiological conditions. While in vivo approaches allow understanding how and where the main expression of this protein is located in SCs arrested in G0, the in vitro studies allow evaluating the expression in cells that are in a proliferative state. One of the contributions of our work lies in the evaluation of the basal culture conditions for the expression of PMP22 in TrJ/+ SCs, compared with that of $+/+$, discriminating the nuclear and cytoplasmic compartments. Overall, in both cellular domains, PMP22 expression was higher in $\mathrm{TrJ} /+$ SCs compared to +/+ SCs. This result is in line, not only with works reporting the existence of cytoplasmic aggregates of PMP22 in TrJ/+ nerves $[14,53,66,67]$ but also in agreement with previous work from our group, which determines PMP22 expression in +/+ and TrJ/+ SCs inside the nucleus [69] (Di Tomaso et al., manuscript under review).

The low dose of curcumin treatment was applied as a possible strategy to stimulate cellular detoxification pathways, and thus alleviate the neurodegenerative phenotype. Our curcumin treatment had an additional effect caused by the $\mathrm{EtOH}$ vehicle (used to let 
curcumin solubilization for ulterior cell entry), in both $+/+$ and $\operatorname{TrJ} /+$ SCs. This collateral effect, observed after six days of treatment, led us to inquire about the use and, more importantly, about the validation of the vehicle so that it could be used without specific effects. In this sense, the recommended vehicles for solubilization of curcumin by the manufacturer are ethanol and dimethyl sulfoxide (DMSO). Although in many papers the effects of the solvents on culture viability are not shown $[37,49,70]$ (or are not discussed $[47,71,72])$, if they do not present cytotoxic effects, the reality is that both vehicles produce effects that vary widely depending on the cell type and duration of treatment [71,73-75]. The pre-established idea of the absence of the effects of these vehicles is recurrent in the literature. However, the contribution of the vehicle prevents us from clearly discriminating the real effect and pharmacological potential of curcumin. For this reason, it must be settled as this constitutes a central point, to circumscribe the results only to the applied treatment. We have tested impact of DMSO as a vehicle of curcumin and our preliminary result seems to indicate an equivalent effect compared to than $\mathrm{EtOH}$ (data not shown). In future work, we will seek to determine other strategies that allow solubilizing and targeting curcumin, evaluating at each step the cell viability to corroborate a negligible effect of the vehicle.

The impact of curcumin on the studied pathways in +/+ SC could not be analyzed in the $\mathrm{TrJ} /+$ genotype, because all markers showed no significant difference between EtOH control and curcumin treatment. The results highlight the lability of the TrJ/+ genotype, expressed in its poor capacity to recover from vehicle impact. In the literature, ethanol has been reported to increase ROS and mitochondrial dysfunction [76-78]. In zebrafish, at concentrations of $1 \%$ ethanol [76], a differential effect in mitochondrial function, with acute and chronic treatment, has been described. However, different performances showed that the mechanisms triggered are also dependent on administration protocols. Since the MTT assay is based on the conversion of tetrazolium to formazan by mitochondrial dehydrogenases, we do not rule out the possibility that ethanol also affects the mitochondria in Schwann cells. Therefore, the increase in the ethanol control relative to the negative control could be due to dehydrogenases functionality changes in response to the vehicle, rather than the normal increase in viability. In this sense, the fact that both genotypes showed equivalent responses in ethanol control to the negative control, supports this hypothesis.

In addition, results found by our group show mitochondrial differences in nerves of +/+ and $\mathrm{TrJ} /+$ mice. From the analysis of electron microscopy images, we obtained the number of mitochondria per fiber in the axonal and SC domains (Fig. S1). These results show that there are differences in the number of mitochondria when comparing SCs of +/+ vs. TrJ/+ fibers. Also, the morphological analysis considering largest and smallest diameters of mitochondria, showed apparent differences between +/+ and TrJ/+ (Fig. S2A). Although there is a correlation between both parameters for the two genotypes, the equations representing the linear correlation are different (Fig. 2SB). Furthermore, when looking at the genome expression, a qPCR analysis of the cytochrome $b$ gene transcript level shows a higher amount of the transcript in +/+ compared to $\operatorname{TrJ} /+$ (Fig. S2C).

Thus, the study of the vehicle takes on particular relevance for in vitro approaches to the autophagy/mTOR and chaperone pathways in the $\mathrm{TrJ} /+$ neurodegenerative genotype.

In the present work, the effect of ethanol was visualized equally between $+/+$ and $\mathrm{TrJ} /+$ SCs, and the percentage of viability was calculated taking as $100 \%$ ethanol control. The latter allowed us to obtain the effect of curcumin to analyze the data. Despite the side effect of ethanol, we were able to determine a $0.25 \mu \mathrm{M}$ curcumin as the lowest concentration that showed no difference in viability to the ethanol control.

From the study of heat-stress markers response pathway, we were able to establish in +/+ SC the HSF1 and Hsp27 expression concordant with that reported in the literature. The HSF1 functions as a transcription factor, which under stress situations is activated and translocated to the nucleus inducing the expression of the pathway's effectors such 
as Hsp27 [79-82]. Furthermore, curcumin treatment allowed us to observe an increase in HSF1 at the nuclear level and a decrease at the cytoplasmic level, together with an increase in Hsp27, indicating a possible activation of this pathway. In addition, HDAC6 expression increased after treatment with curcumin. This increase of the protein, a member of basal autophagy involved in the selective elimination of aberrant protein aggregates $[83,84]$ suggests that in the wild-type genotype, curcumin treatment may be stimulating this degradation pathway. Conversely, the increase in ribosomal expression under mTOR regulation $[85,86]$ supports the idea of a favorable nutritional and energetic context in $+/+$ SC after curcumin treatment.

The impact of curcumin on the studied pathways in +/+ SC could not be analyzed in the $\mathrm{TrJ} /+$ genotype because all markers showed no significant difference between EtOH control and curcumin treatment. These results indicate a $\mathrm{TrJ} /+$ genotype lability that prevents SC recovering from the ethanol shock. Thus, the study of the vehicle takes on particular relevance for in vitro approaches to the autophagy/mTOR and chaperone pathways in the $\operatorname{Tr} \mathrm{J} /+$ neurodegenerative genotype.

In the horizon of the $\mathrm{TrJ} /+$ in vitro approaches, and its response to the action of different neuroprotective and anti-inflammatory agents, such as curcumin, the analysis of the effects of the vehicle itself is an essential, inescapable, and conditioning step for the finetuning of the experimental strategy to be applied.

\section{Conclusions}

Our work established a new experimental strategy for obtaining enriched cultures of SC from +/+ and $\mathrm{TrJ} /+$ mice. We were able to determine a curcumin concentration with no effect on viability in both genotypes for an extended period of time, which allowed us to study the expression of key autophagic-pathway markers in the accumulation of PMP22 protein in SCs. We found an intrinsic ethanol effect in +/+ and $\mathrm{TrJ} /+\mathrm{SC}$ that was reversed by curcumin treatment in $+/+$, but not in $\mathrm{TrJ} /+$ SC. These in vitro cultures allow pre-clinical investigations of promising therapeutic strategies or pharmacological compounds such as curcumin, for the alleviation of human-related peripheral neuropathies.

Supplementary Materials: Figure S1: Mitochondrial distribution in fibers of $\operatorname{Tr} \mathrm{J} /+$ and +/+ mice, Figure S2: Morphology and differential gene expression in mitochondria of SCs from $\mathrm{TrJ} /+$ and $+/+$ mice.

Author Contributions: Conceptualization, L.V.A., G.R., M.C., M.V.D.T., and A.K.; methodology, L.V.A., G.R., and A.K.; software, L.V.A., and A.K.; validation, L.V.A., M.C., and A.K.; formal analysis, L.V.A., and A.K.; investigation, L.V.A., G.R., L.V., C.R., J.F. and A.K.; resources, A.K.; data curation, L.V.A., and A.K.; writing-original draft preparation, L.V.A., and A.K.; writing-review and editing, L.V.A., G.R., M.C., M.V.D.T., and A.K.; visualization, L.V.A., G.R. and A.K.; supervision, A.K.; project administration, A.K.; funding acquisition, A.K. All authors have read and agreed to the published version of the manuscript.

Funding: This research was funded by the Comisión Sectorial de Investigación Científica de la Universidad de la República (CSIC-UdelaR); Agencia Nacional de Investigación e Innovación (ANII) and the Programa de Desarrollo de Ciencias Básicas (PEDECIBA).

Institutional Review Board Statement: The experimental procedures were approved by the local Ethics Committee (CEUA-IIBCE, MEC, Uruguay, protocol number: 002a/10/2020).

Informed Consent Statement: Not applicable.

Data Availability Statement: Data available on request due to restrictions e.g., privacy or ethical. The data presented in this study are available on request from the corresponding author.

Conflicts of Interest: The authors declare no conflict of interest. 
1. Skre, H. Genetic and clinical aspects of Charcot-Marie-Tooth's disease. Clin. Genet. 1974, 6, 98-118, doi:10.1111/j.1399-0004.1974.tb00638.x.

2. Vallat, J.M. Dominantly inherited peripheral neuropathies. J. Neuropathol. Exp. Neurol. 2003, 62, 699-714, doi:10.1093/jnen/62.7.699.

3. Bird, T.D. Charcot-Marie-Tooth (CMT) Hereditary Neuropathy Overview; University of Washington, Seattle, 1993;

4. Fortun, J.; Dunn, W.A.; Joy, S.; Li, J.; Notterpek, L. Emerging role for autophagy in the removal of aggresomes in Schwann cells. J. Neurosci. 2003, 23, 10672-80, doi:23/33/10672 [pii].

5. Okamoto, Y.; Pehlivan, D.; Wiszniewski, W.; Beck, C.R.; Snipes, G.J.; Lupski, J.R.; Khajavi, M. Curcumin facilitates a transitory cellular stress response in trembler-J mice. Hum. Mol. Genet. 2013, 22, 4698-4705, doi:10.1093/hmg/ddt318.

6. Suter, U.; Scherer, S.S. Disease mechanisms in inherited neuropathies. Nat. Rev. Neurosci. 2003, 4, 714-726, doi:10.1038/nrn1196.

7. Jaradeh, S.S. Hereditary Neuropathies. J. Clin. Neuromuscul. Dis. 2003, 5, 72-80, doi:10.1097/00131402-20031200000002.

8. Valentijn, L.J.; Baas, F.; Wolterman, R.A.; Hoogendijk, J.E.; van den Bosch, N.H.A.; Zorn, I.; Gabreëls-Festen, A.A.W.M.; de Visser, M.; Bolhuis, P.A. Identical point mutations of PMP-22 in Trembler-J mouse and CharcotMarie-Tooth disease type 1A. Nat. Genet. 1992, 2, 288-291, doi:10.1038/ng1292-288.

9. Notterpek, L.; Ryan, M.C.; Tobler, A.R.; Shooter, E.M. PMP22 accumulation in aggresomes: Implications for CMT1A pathology. Neurobiol. Dis. 1999, 6, 450-460, doi:10.1006/nbdi.1999.0274.

10. Pareek, S.; Notterpek, L.; Snipes, G.J.; Naef, R.; Sossin, W.; Laliberté, J.; Iacampo, S.; Suter, U.; Shooter, E.M.; Murphy, R.A. Neurons promote the translocation of peripheral myelin protein 22 into myelin. J. Neurosci. 1997, 17, 7754-7762, doi:10.1523/jneurosci.17-20-07754.1997.

11. Kun, A.; Rosso, G.; Canclini, L.; Bresque, M.; Romeo, C.; Cal, K.; Calliari, A.; Hanuz, A.; Roberto, J.; Roberto, J. The Schwann Cell-Axon Link in Normal Condition or Neuro-Degenerative Diseases: An Immunocytochemical Approach. In Applications of Immunocytochemistry; Dehghani, H., Ed.; InTech: London, Switzerland, 2012; pp. 249-266 ISBN 978-953-51-5235-4.

12. Myers, J.K.; Mobley, C.K.; Sanders, C.R. The Peripheral Neuropathy-Linked Trembler and Trembler-J Mutant Forms of Peripheral Myelin Protein 22 are Folding- Destabilized. Biochemistry 2008, 47, 10620-10629, doi:10.1161/CIRCULATIONAHA.110.956839.

13. Pantera, H.; Shy, M.E.; Svaren, J. Regulating PMP22 expression as a dosage sensitive neuropathy gene. Brain Res. 2020, 1726, doi:10.1016/j.brainres.2019.146491.

14. Kun, A.; Canclini, L.; Rosso, G.; Bresque, M.; Romeo, C.; Hanusz, A.; Cal, K.; Calliari, A.; Sotelo Silveira, J.; Sotelo, J.R. F-actin distribution at nodes of Ranvier and Schmidt-Lanterman incisures in mammalian sciatic nerves. Cytoskeleton 2012, 69, 486-495, doi:10.1002/cm.21011.

15. Rosso, G.; Negreira, C.; Sotelo, J.R.; Kun, A. Myelinating and demyelinating phenotype of Trembler-J mouse (a model of Charcot-Marie-Tooth human disease) analyzed by atomic force microscopy and confocal microscopy. J. Mol. Recognit. 2012, 25, 247-255, doi:10.1002/jmr.2176.

16. Notterpek, L.; Shooter, E.M.; Snipes, G.J. Upregulation of the endosomal-lysosomal pathway in the Trembler-J neuropathy. J. Neurosci. 1997, 17, 4190-4200, doi:10.1523/jneurosci.17-11-04190.1997.

17. Khalil, A.A.; Kabapy, N.F.; Deraz, S.F.; Smith, C. Heat shock proteins in oncology: Diagnostic biomarkers or therapeutic targets? Biochim. Biophys. Acta - Rev. Cancer 2011, 1816, 89-104, doi:10.1016/j.bbcan.2011.05.001.

18. Borges, T.J.; Wieten, L.; Van Herwijnen, M.J.C.; Broere, F.; Van der Zee, R.; Bonorino, C.; Van Eden, W. The antiinflammatory mechanisms of Hsp70. Front. Immunol. 2012, 3, 1-12, doi:10.3389/fimmu.2012.00095. 
19. Chou, S.D.; Prince, T.; Gong, J.; Calderwood, S.K. mTOR is essential for the proteotoxic stress response, HSF1 activation and heat shock protein synthesis. PLoS One 2012, 7, 1-9, doi:10.1371/journal.pone.0039679.

20. Morimoto, R.I. Regulation of the heat-shock transcriptional response: cross talk between a family of heat-shock factors, molecular chaperones, and negative regulators. Genes Dev 1998, 12, 3788-3796, doi:10.1101/gad.12.24.3788.

21. Christie, M.; Chang, C.W.; Róna, G.; Smith, K.M.; Stewart, A.G.; Takeda, A.A.S.; Fontes, M.R.M.; Stewart, M.; Vértessy, B.G.; Forwood, J.K.; et al. Structural Biology and Regulation of Protein Import into the Nucleus. J. Mol. Biol. 2016, 428, 2060-2090, doi:10.1016/j.jmb.2015.10.023.

22. Home, T.; Jensen, R.A.; Rao, R. Heat shock factor 1 in protein homeostasis and oncogenic signal integration. Cancer Res. 2015, 75, 907-912, doi:10.1158/0008-5472.CAN-14-2905.

23. Watanabe, Y.; Tsujimura, A.; Taguchi, K.; Tanaka, M. HSF1 stress response pathway regulates autophagy receptor SQSTM1/p62-associated proteostasis. Autophagy 2017, 13, 133-148, doi:10.1080/15548627.2016.1248018.

24. Schäfer, C.; Seeliger, H.; Bader, D.C.; Assmann, G.; Buchner, D.; Guo, Y.; Ziesch, A.; Palagyi, A.; Ochs, S.; Laubender, R.P.; et al. Heat shock protein 27 as a prognostic and predictive biomarker in pancreatic ductal adenocarcinoma. J. Cell. Mol. Med. 2012, 16, 1776-91, doi:10.1111/j.1582-4934.2011.01473.x.

25. Garrido, C.; Brunet, M.; Didelot, C.; Zermati, Y.; Schmitt, E.; Kroemer, G. Heat shock proteins 27 and 70 : Antiapoptotic proteins with tumorigenic properties. Cell Cycle 2006, 5, 2592-2601, doi:10.4161/cc.5.22.3448.

26. Arrigo, A.-P.; Gibert, B. HspB1, HspB5 and HspB4 in Human Cancers: Potent Oncogenic Role of Some of Their Client Proteins; 2014; Vol. 6; ISBN 3304787828.

27. Choi, S.; Lee, H.-J.; Jin, Y.B.; Jang, J.; Kang, G.; Lee, M.; Kim, C.-H.; Kim, J.; Yoon, S.S.; Lee, Y.; et al. MMP9 processing of HSPB1 regulates tumor progression. PLoS One 2014, 9, e85509, doi:10.1371/journal.pone.0085509.

28. Vidyasagar, A.; Wilson, N.A.; Djamali, A. Heat shock protein 27 (HSP27): biomarker of disease and therapeutic target. Firogenes. Tissue Repairs 2012, 27, 1-7, doi:10.1186/1755-1536-5-7.

29. Konishi, H.; Matsuzaki, H.; Tanaka, M.; Takemura, Y.; Kuroda, S.; Ono, Y.; Kikkawa, U. Activation of protein kinase B (Akt/RAC-protein kinase) by cellular stress and its association with heat shock protein Hsp27. FEBS Lett. 1997, 410, 493-498, doi:10.1016/S0014-5793(97)00541-3.

30. Wu, R.; Kausar, H.; Johnson, P.; Montoya-Durango, D.E.; Merchant, M.; Rane, M.J. Hsp27 regulates Akt activation and polymorphonuclear leukocyte apoptosis by scaffolding MK2 to Akt signal complex. J. Biol. Chem. 2007, 282, 21598-21608, doi:10.1074/jbc.M611316200.

31. Rane, M.J.; Pan, Y.; Singh, S.; Powell, D.W.; Wu, R.; Cummins, T.; Chen, Q.; McLeish, K.R.; Klein, J.B. Heat shock protein 27 controls apoptosis by regulating Akt activation. J. Biol. Chem. 2003, 278, 27828-27835, doi:10.1074/jbc.M303417200.

32. Chittoor-Vinod, V.G.; Lee, S.; Judge, S.M.; Notterpek, L. Inducible HSP70 is critical in preventing the aggregation and enhancing the processing of PMP22. ASN Neuro 2015, 7, 1-17, doi:10.1177/1759091415569909.

33. Fortun, J.; Verrier, J.D.; Go, J.C.; Madorsky, I.; Dunn, W.A.; Notterpek, L. The formation of peripheral myelin protein 22 aggregates is hindered by the enhancement of autophagy and expression of cytoplasmic chaperones. Neurobiol. Dis. 2007, 25, 252-265, doi:10.1016/j.nbd.2006.09.018.

34. Benoy, V.; Vanden Berghe, P.; Jarpe, M.; Van Damme, P.; Robberecht, W.; Van Den Bosch, L. Development of Improved HDAC6 Inhibitors as Pharmacological Therapy for Axonal Charcot-Marie-Tooth Disease. Neurotherapeutics 2017, 14, 417-428, doi:10.1007/s13311-016-0501-z.

35. Novelle, M.G.; Davis, A.; Price, N.L.; Ali, A.; Fürer-Galvan, S.; Zhang, Y.; Becker, K.; Bernier, M.; de Cabo, R. Caloric restriction induces heat shock response and inhibits B16F10 cell tumorigenesis both in vitro and in vivo. Aging (Albany. NY). 2015, 7, 233-240, doi:10.18632/aging.100732. 
36. Li, J.; Zhang, C.-X.; Liu, Y.-M.; Chen, K.-L.; Chen, G. A comparative study of anti-aging properties and mechanism: resveratrol and caloric restriction. Oncotarget 2017, 8, 65717-65729, doi:10.18632/oncotarget.20084.

37. Soh, J.W.; Marowsky, N.; Nichols, T.J.; Rahman, A.M.; Miah, T.; Sarao, P.; Khasawneh, R.; Unnikrishnan, A.; Heydari, A.R.; Silver, R.B.; et al. Curcumin is an early-acting stage-specific inducer of extended functional longevity in Drosophila. Exp. Gerontol. 2013, 48, 229-239, doi:10.1016/j.exger.2012.09.007.

38. Sinclair, D.A. Toward a unified theory of caloric restriction and longevity regulation. Mech. Ageing Dev. 2005, 126, 987-1002, doi:10.1016/j.mad.2005.03.019.

39. Kume, S.; Uzu, T.; Kashiwagi, A.; Koya, D. SIRT1, a Calorie Restriction Mimetic, in a New Therapeutic Approach for Type 2 Diabetes Mellitus and Diabetic Vascular Complications. Endocrine, Metab. Immune Disord. - Drug Targets 2012, 10, 16-24, doi:10.2174/187153010790827957.

40. Willcox, B.J.; Willcox, D.C. Caloric restriction, caloric restriction mimetics, and healthy aging in Okinawa: Controversies and clinical implications. Curr. Opin. Clin. Nutr. Metab. Care 2014, 17, 51-58, doi:10.1097/MCO.0000000000000019.

41. Singh, S.; Garg, G.; Singh, A.K.; Bissoyi, A.; Rizvi, S.I. Fisetin, a potential caloric restriction mimetic, attenuates senescence biomarkers in rat erythrocytes. Biochem. Cell Biol. 2019, 97, 480-487, doi:10.1139/bcb-2018-0159.

42. Ingram, D.K.; Zhu, M.; Mamczarz, J.; Zou, S.; Lane, M.A.; Roth, G.S.; deCabo, R. Calorie restriction mimetics: An emerging research field. Aging Cell 2006, 5, 97-108, doi:10.1111/j.1474-9726.2006.00202.x.

43. Mariño, G.; Pietrocola, F.; Madeo, F.; Kroemer, G. Caloric restriction mimetics: Natural/physiological pharmacological autophagy inducers. Autophagy 2014, 10, 1879-1882, doi:10.4161/auto.36413.

44. Madeo, F.; Pietrocola, F.; Eisenberg, T.; Kroemer, G. Caloric restriction mimetics: Towards a molecular definition. Nat. Rev. Drug Discov. 2014, 13, 727-740, doi:10.1038/nrd4391.

45. Khandelwal, P.; Alam, A.; Choksi, A.; Chattopadhyay, S.; Poddar, P. Retention of Anticancer Activity of Curcumin after Conjugation with Fluorescent Gold Quantum Clusters: An in Vitro and in Vivo Xenograft Study. ACS Omega 2018, 3, 4776-4785, doi:10.1021/acsomega.8b00113.

46. Beevers, C.S.; Li, F.; Liu, L.; Huang, S. Curcumin inhibits the mammalian target of rapamycin-mediated signaling pathways in cancer cells. Int. J. Cancer 2006, 119, 757-764, doi:10.1002/ijc.21932.

47. Watson, J.L.; Hill, R.; Yaffe, P.B.; Greenshields, A.; Walsh, M.; Lee, P.W.; Giacomantonio, C.A.; Hoskin, D.W. Curcumin causes superoxide anion production and p53-independent apoptosis in human colon cancer cells. Cancer Lett. 2010, 297, 1-8, doi:10.1016/j.canlet.2010.04.018.

48. Caillaud, M.; Msheik, Z.; Ndong-Ntoutoume, G.M.A.; Vignaud, L.; Richard, L.; Favreau, F.; Faye, P.A.; Sturtz, F.; Granet, R.; Vallat, J.M.; et al. Curcumin-cyclodextrin/cellulose nanocrystals improve the phenotype of Charcot-Marie-Tooth-1A transgenic rats through the reduction of oxidative stress. Free Radic. Biol. Med. 2020, 161, 246-262, doi:10.1016/j.freeradbiomed.2020.09.019.

49. Barzegar, A.; Moosavi-Movahedi, A.A. Intracellular ROS protection efficiency and free radical-scavenging activity of curcumin. PLoS One 2011, 6, 1-7, doi:10.1371/journal.pone.0026012.

50. Kang, S.K.; Cha, S.H.; Jeon, H.G. Curcumin-induced histone hypoacetylation enhances caspase-3-dependent glioma cell death and neurogenesis of neural progenitor cells. Stem Cells Dev. 2006, 15, 165-174, doi:10.1089/scd.2006.15.165.

51. Liu, X.; You, L.; Tarafder, S.; Zou, L.; Fang, Z.; Chen, J.; Lee, C.H.; Zhang, Q. Curcumin-releasing chitosan/aloe membrane for skin regeneration. Chem. Eng. J. 2019, 359, 1111-1119, doi:10.1016/j.cej.2018.11.073.

52. Thaloor, D.; Miller, K.J.; Gephart, J.; Mitchell, P.O.; Pavlath, G.K. Systemic administration of the NF- $\kappa B$ inhibitor curcumin stimulates muscle regeneration after traumatic injury. Am. J. Physiol. - Cell Physiol. 1999, 277, doi:10.1152/ajpcell.1999.277.2.c320. 
53. Khajavi, M.; Shiga, K.; Wiszniewski, W.; He, F.; Shaw, C.A.; Yan, J.; Wensel, T.G.; Snipes, G.J.; Lupski, J.R. Oral Curcumin Mitigates the Clinical and Neuropathologic Phenotype of the Trembler-J Mouse: A Potential Therapy for Inherited Neuropathy. Am. J. Hum. Genet. 2007, 81, 438-453, doi:10.1086/519926.

54. Fortun, J.; Go, J.C.; Li, J.; Amici, S.A.; Dunn, W.A.; Notterpek, L. Alterations in degradative pathways and protein aggregation in a neuropathy model based on PMP22 overexpression. Neurobiol. Dis. 2006, 22, 153-164, doi:10.1016/j.nbd.2005.10.010.

55. Rosso, G.; Liashkovich, I.; Young, P.; Röhr, D.; Shahin, V. Schwann cells and neurite outgrowth from embryonic dorsal root ganglions are highly mechanosensitive. Nanomedicine Nanotechnology, Biol. Med. 2017, 13, 493-501, doi:10.1016/j.nano.2016.06.011.

56. Kreider, B.Q.; Messing, A.; Doan, H.; Kim, S.U.; Lisak, R.P.; Pleasure, D.E. Enrichment of Schwann cell cultures from neonatal rat sciatic nerve by differential adhesion. Brain Res. 1981, 3, 54-67.

57. Li, R. Culture methods for selective growth of normal rat and human Schwann cells. Methods Cell Biol. 1998, 57, 167-186, doi:10.1016/s0091-679x(08)61577-0.

58. Mauritz, C.; Grothe, C.; Haastert, K. Comparative study of cell culture and purification methods to obtain highly enriched cultures of proliferating adult rat Schwann cells. J. Neurosci. Res. 2004, 77, 453-461, doi:10.1002/jnr.20166.

59. Caillaud, M.; Chantemargue, B.; Richard, L.; Vignaud, L.; Favreau, F.; Faye, P. ierre-A.; Vignoles, P.; Sturtz, F.; Trouillas, P.; Vallat, J.; et al. Local low dose curcumin treatment improves functional recovery and remyelination in a rat model of sciatic nerve crush through inhibition of oxidative stress. Neuropharmacology 2018, 139, 98-116, doi:10.1016/j.neuropharm.2018.07.001.

60. Li, W.; Sun, K.; Hu, F.; Chen, L.; Zhang, X.; Wang, F.; Yan, B. Protective effects of natural compounds against oxidative stress in ischemic diseases and cancers via activating the Nrf2 signaling pathway: A mini review. J. Biochem. Mol. Toxicol. 2020, 1-13, doi:10.1002/jbt.22658.

61. Lundvig, D.M.S.; Pennings, S.W.C.; Brouwer, K.M.; Mtaya-Mlangwa, M.; Mugonzibwa, E.A.; Kuijpers-Jagtman, A.M.; Von den Hoff, J.W.; Wagener, F.A.D.T.G. Curcumin induces differential expression of cytoprotective enzymes but similar apoptotic responses in fibroblasts and myofibroblasts. Exp. Cell Res. 2015, 330, 429-441, doi:10.1016/j.yexcr.2014.10.006.

62. Zhang, W.; Li, Q.; Yang, C.; Yang, H.; Rao, J.; Zhang, X. Curcumin exerts anti-tumor effects on diffuse large B cell lymphoma via regulating PPAR $\gamma$ expression. Biochem. Biophys. Res. Commun. 2020, 524, 70-76, doi:10.1016/j.bbrc.2019.12.129.

63. Mosmann, T. Rapid colorimetric assay for cellular growth and survival: Application to proliferation and cytotoxicity assays. J. Immunol. Methods 1983, 65, 55-63, doi:10.1016/0022-1759(83)90303-4.

64. Zhou, Y.; Bazick, H.; Miles, J.R.; Fethiere, A.I.; Salihi, M.O. Al; Fazio, S.; Tavori, H.; Notterpek, L. A neutral lipidenriched diet improves myelination and alleviates peripheral nerve pathology in neuropathic mice. Exp. Neurol. 2019, 321, 113031, doi:10.1016/j.expneurol.2019.113031.

65. Hara, T.; Nakamura, K.; Matsui, M.; Yamamoto, A.; Nakahara, Y.; Suzuki-Migishima, R.; Yokoyama, M.; Mishima, K.; Saito, I.; Okano, H.; et al. Suppression of basal autophagy in neural cells causes neurodegenerative disease in mice. Nature 2006, 441, 885-889, doi:10.1038/nature04724.

66. Fortun, J.; Li, J.; Go, J.C.; Fenstermaker, A.; Fletcher, B.S.; Notterpek, L. Impaired proteasome activity and accumulation of ubiquitinated substrates in a hereditary neuropathy model. J. Neurochem. 2005, 92, 1531-1541, doi:10.1111/j.1471-4159.2004.02987.x.

67. Ryan, M.C.; Shooter, E.M.; Notterpek, L. Aggresome formation in neuropathy models based on peripheral myelin protein 22 mutations. Neurobiol. Dis. 2002, 10, 109-118, doi:10.1006/nbdi.2002.0500.

68. Pareek, S.; Suter, U.; Snipes, G.J.; Welcher, A.A.; Shooter, E.M.; Murphy, R.A. Detection and processing of 
peripheral myelin protein PMP22 in cultured Schwann cells. J. Biol. Chem. 1993, 268, 10372-10379, doi:10.1016/s0021-9258(18)82211-6.

69. Damián, J.P.; Vázquez Alberdi, L.; Canclini, L.; Rosso, G.; Bravo, S.O.; Martínez, M.; Uriarte, N.; Ruiz, P.; Calero, M.; Di Tomaso, M.V.; et al. Central Alteration in Peripheral Neuropathy of Trembler-J Mice: Hippocampal pmp22 Expression and Behavioral Profile in Anxiety Tests. Biomolecules 2021, 11, 601, doi:10.3390/biom11040601.

70. Tello Velasquez, J.; Watts, M.E.; Todorovic, M.; Nazareth, L.; Pastrana, E.; Diaz-Nido, J.; Lim, F.; Ekberg, J.A.K.; Quinn, R.J.; St John, J.A. Low-dose curcumin stimulates proliferation, migration and phagocytic activity of olfactory ensheathing cells. PLoS One 2014, 9, doi:10.1371/journal.pone.0111787.

71. Zhao, Z.; Li, X.; Li, Q. Curcumin accelerates the repair of sciatic nerve injury in rats through reducing Schwann cells apoptosis and promoting myelinization. Biomed. Pharmacother. 2017, 92, 1103-1110, doi:10.1016/j.biopha.2017.05.099.

72. Abuelba, H.; Cotrutz, C.E.; Stoica, B.A.; Stoica, L.; Olinici, D.; Petreuş, T. In vitro evaluation of curcumin effects on breast adenocarcinoma 2D and 3D cell cultures. Rom. J. Morphol. Embryol. 2015, 56, 71-76.

73. Galvao, J.; Davis, B.; Tilley, M.; Normando, E.; Duchen, M.R.; Cordeiro, M.F. Unexpected low-dose toxicity of the universal solvent DMSO. FASEB J. 2014, 28, 1317-1330, doi:10.1096/fj.13-235440.

74. Ilieva, Y.; Dimitrova, L.; Zaharieva, M.M.; Kaleva, M.; Alov, P.; Tsakovska, I.; Pencheva, T.; Pencheva-El Tibi, I.; Najdenski, H.; Pajeva, I. Cytotoxicity and Microbicidal Activity of Commonly Used Organic Solvents: A Comparative Study and Application to a Standardized Extract from Vaccinium macrocarpon. Toxics 2021, 9, 92, doi:10.3390/toxics9050092.

75. Adler, S.; Pellizzer, C.; Paparella, M.; Hartung, T.; Bremer, S. The effects of solvents on embryonic stem cell differentiation. Toxicol. Vitr. 2006, 20, 265-271, doi:10.1016/j.tiv.2005.06.043.

76. Müller, T.E.; Nunes, M.E.M.; Rodrigues, N.R.; Fontana, B.D.; Hartmann, D.D.; Franco, J.L.; Rosemberg, D.B. Neurochemical mechanisms underlying acute and chronic ethanol-mediated responses in zebrafish: The role of mitochondrial bioenergetics. Neurochem. Int. 2019, 131, doi:10.1016/j.neuint.2019.104584.

77. Pereira, R.B.; Andrade, P.B.; Valentão, P. A Comprehensive View of the Neurotoxicity Mechanisms of Cocaine and Ethanol. Neurotox. Res. 2015, 28, 253-267, doi:10.1007/s12640-015-9536-x.

78. Yang, F.; Luo, J. Endoplasmic reticulum stress and ethanol neurotoxicity. Biomolecules 2015, 5, 2538-2553, doi:10.3390/biom5042538.

79. Gomez-Pastor, R.; Burchfiel, E.T.; Thiele, D.J. Regulation of heat shock transcription factors and their roles in physiology and disease. Nat. Rev. Mol. Cell Biol. 2017, doi:10.1038/nrm.2017.73.

80. Arrigo, A.-P. Structure-functions of HspB1 (Hsp27). Methods Mol. Biol. 2011, 787, 105-119, doi:10.1007/978-161779-295-3_9.

81. Strauch, A.; Haslbeck, M. The function of small heat-shock proteins and their implication in proteostasis. Essays Biochem. 2016, 60, 163-172, doi:10.1042/EBC20160010.

82. Huang, C.; Wu, J.; Xu, L.; Wang, J.; Chen, Z.; Yang, R. Regulation of HSF1 protein stabilization: An updated review. Eur. J. Pharmacol. 2018, 822, 69-77, doi:10.1016/j.ejphar.2018.01.005.

83. Lee, J.Y.; Koga, H.; Kawaguchi, Y.; Tang, W.; Wong, E.; Gao, Y.S.; Pandey, U.B.; Kaushik, S.; Tresse, E.; Lu, J.; et al. HDAC6 controls autophagosome maturation essential for ubiquitin-selective quality-control autophagy. EMBO J. 2010, 29, 969-980, doi:10.1038/emboj.2009.405.

84. Richter-Landsberg, C.; Leyk, J. Inclusion body formation, macroautophagy, and the role of HDAC6 in neurodegeneration. Acta Neuropathol. 2013, 126, 793-807, doi:10.1007/s00401-013-1158-x.

85. Mayer, C.; Grummt, I. Ribosome biogenesis and cell growth: mTOR coordinates transcription by all three classes of nuclear RNA polymerases. Oncogene 2006, 25, 6384-6391. 
86. Sarbassov, D.D.; Ali, S.M.; Sabatini, D.M. Growing roles for the mTOR pathway. Curr. Opin. Cell Biol. 2005, 17, 596-603, doi:10.1016/j.ceb.2005.09.009. 